\title{
25 Research Square \\ Glutamic Acid Reshapes The Phytobiome To Protect Plants Against Pathogens
}

\section{Da-Ran Kim}

Gyeongsang National University

Chang-Wook Jeon

Gyeongsang National University

Gyeongjun Cho

Gyeongsang National University

\section{Linda Thomashow}

USDA-ARS

David Weller

USDA-ARS

Man-Jeong Paik

Sunchon National University

\section{Yong Bok Lee}

Gyeongsang National University

\section{Youn-Sig Kwak ( $\square$ kwak@gnu.ac.kr)}

Gyeongsang National Univesity https://orcid.org/0000-0003-2139-1808

\section{Research}

Keywords: Microbiome engineering, glutamic acid, Streptomyces, phytobiome

Posted Date: November 17th, 2020

DOI: https://doi.org/10.21203/rs.3.rs-104575/v1

License: (c) (1) This work is licensed under a Creative Commons Attribution 4.0 International License.

Read Full License 


\section{Abstract}

Background: The physiology and growth of plants are strongly influenced by their associated microbiomes. Conversely, the composition of the phytobiome is flexible, responding to the state of the host and raising the possibility that it can be engineered to benefit the plant. However, technology for engineering the structure of the microbiome is not yet available.

Results: Here we show that glutamic acid reshapes the plant microbial community and enriches populations of Streptomyces, a functional core microbe, both above and below ground, in strawberry and tomato. Upon application of glutamic acid, the population size of Streptomyces increased dramatically in the anthosphere and the rhizosphere. At the same time, diseases caused by species of Fusarium were significantly reduced in both habitats. Plant resistance-related genes were not activated, suggesting that glutamic acid modulates the microbiome community directly, rather than activating the host's own protective mechanisms.

Conclusions: Much is known about the structure of plant-associated microbial communities, but little has been learned about how the community composition and complexity are controlled. Our results demonstrate that the microbiome community can be engineered and unlock the mode of action of glutamic acid.

\section{Introduction}

The plant microbiome includes associated microorganisms residing above and below ground, and inside or outside of plant tissues [1]. Plants in nature interact endlessly with diverse microbial species including mutualists that influence plant health and reproduction by providing phytohormones, fixing nitrogen, solubilizing phosphorus, facilitating mineral uptake, and protecting against pathogen attack [2-12]. Because plant microbiomes play a critical role in plant development and health [13-15], it is reasonable that maintenance of a healthy microbiome would promote growth and crop yield in agricultural systems $[16,17]$. Our understanding of the plant-associated microbial community has expanded in recent years to include less abundant or even unculturable taxa, resulting in awareness of interactions with an everincreasing microbial diversity and recognition that plants do not exhibit normal growth and physiology without interactions with their associated microbes [18-20]. This ecological and functional integration of the plant and its microbiome is encompassed within the holobiont, the assemblage of the host and the other species living in or around it, which together form a discrete ecological unit. Moreover, complex microbial populations reside in association with all plant tissues, implying that the initial phases of colonization, as well as subsequent microbe-microbe interactions, selectively influence the structure of the microbiome $[19,21-23]$ and that the core microbial community has a vital role in the overall microbiome stability and the fitness of the host $[24,25]$.

Trends in plant microbiome studies have approached microbiome engineering with the goal of improving plant health and productivity [26] via either top-down or bottom-up approaches [25]. The top-down 
approach refers to manipulation of environmental and physicochemical conditions to select the desired biological process $[9,27]$. This top-down design involves relatively macro-scale processes resulting in microbiome engineering. Conversely, bottom-up approaches link molecular and biochemical characteristics and relatively micro-scale processes with precise mechanisms in the interaction [27]. Consequently, these approaches are flexible enough to be applied to microbiome-associated phenotypes [27]. In humans or animals, they can be facilitated by prebiotics, a terminology invented in 1995 by Gibson and Roberfroid [28]. Such prebiotics may selectively influence the gut microbiome [29-32] or move to other organs through the blood, directly influencing animal health [33]. In botanical systems, a similar role is played by biostimulators [34], defined as substances applied to plants with the aim to enhance nutrition efficiency, abiotic stress tolerance and/or crop quality traits, regardless of nutrient content $[35,36]$. In recent years, the terminology has been extended in scope from screening substances to understanding their mode-of-action $[37,38]$. Thus, humic acid, fulvic acid, and seaweed extract were identified as biostimulators that enhanced tolerance against abiotic stress, promoted plant growth, and improved soil quality [35,37]. Such biostimulators may contain plant hormone-like compounds or activate hormone activities as their mode-of-action but so far, the mechanisms underpinning biostimulator function are poorly understood [37].

We previously observed collapse of the anthosphere microbial community structure coincident with the aging of strawberry plants [6]. In particular, the loss of diversity and reduction in population density of Streptomyces globisporus SP6C4, a core microbe, was negatively correlated with onset of two major anthosphere diseases, gray mold (Botrytis cinerea) which includes brown spots on flower petals, and blossom blight (Cladosporioides sp.), which appears as fuzzy gray mycelium on flower pistils and stamens. We then hypothesized that a specific plant metabolite could be amended to rebuild the microbial community structure to maintain the health of the plant. Here, we propose that glutamic acid configures the microbial community and modulates the abundance of S. globisporus SP6C4.

\section{Results}

\section{Microbiome collapse and disease}

The microbial community in strawberry flowers shifts throughout the growing season from one of high diversity (weeks $0-12$ ) to one of low diversity (weeks 14-24), a pattern coincident with the loss of $S$. globisporus SP6C4, which we consider to be a core member of the flower microbial community [6]. Here, we recalculated strawberry flower microbial population data to identify the top 10 OTUs and the diversity of the microbial community throughout the growing season (Fig. 1a). In contrast to the incidence of gray mold disease, which increased from weeks 14-24, diversity in the anthosphere community during weeks 1-12 collapsed on week 14 at a time coincident with the onset of disease in plants exposed to the pathogen (Fig. 1b,c). These patterns indicated that the microbial community structure changed with the age of the plant or stage of blossoming, and that the collapse of the community included loss of the core microbial population. 


\section{Effect of plant exudates on the core microbe}

Petal and ovary samples were analyzed for amino acids, organic acids and soluble sugars (Fig. 1d and Additional file 1: Figure S1). Amino acids in the petals did not differ significantly throughout periods of low and high disease incidence except for glutamic acid and proline, the content of which decreased significantly during the period of high gray mold disease incidence. In contrast, the content of the 23 amino acids in the flower ovary did not vary regardless of disease incidence (Additional file 1: Figure S1a). Unlike the situation with amino acids, the content of soluble sugars and organic acids in petals and ovaries did not differ between periods of low and high disease (Additional file 1: Figure S1b,c,d). These findings suggest that glutamic acid and proline have a key role in maintaining microbial diversity and the density of the core bacterium SP6C4 in the anthosphere. Biolog plates PM1 and PMB3 were used to identify carbon (PM1) and nitrogen (PMB3) sources influencing the core strain. S. globisporus SP6C4 grew equally well on the carbon substrates (Additional file 1: Figure S2a and Additional file 2: Table S1), but growth on nitrogen substrates increased markedly on L-tyrosine, L-proline, L-aspartic acid, L-cysteine, agmatine, and L-glutamic acid $\left(\mathrm{OD}_{590} \geq 0.4\right)$ (Additional file 1: Figure S2b and Additional file 2: Table S2). However, only L-glutamic acid influenced the growth of S. globisporus SP6C4 in both the amino acid analysis of flowers and the Biolog plates. Bacterial growth was further evaluated with the four amino acids L-glutamic acid, L-proline, aspartic acid, and L-tyrosine, with basal medium and L-asparagine as negative controls and L-tryptophan as a positive control. SP6C4 did not grow on unamended basal medium, but growth at $\mathrm{OD}_{600}$ was 0.6 for L-asparagine, 0.7 for aspartic acid, 0.8 for L-proline, 0.8 for Ltryptophan and 1.3 for L-glutamic acid (Fig. 1e). As additional assessment, growth on each amino acid was evaluated at $0.02 \%, 0.2 \%$ and $2 \%$ (Fig. $1 \mathrm{f}$ and Additional file 1: Figure S2c,d) in basal medium. Regardless of concentration, L-glutamic acid had the greatest effect on the growth of SP6C4.

\section{Effect of glutamic acid on anthosphere diseases}

To investigate the effect of L-glutamic acid on the occurrence of gray mold and blossom blight diseases and the density of strain SP6C4 in strawberry flowers, disease incidence (DI) was evaluated at two-week intervals. At the same time, L-glutamic acid and L-asparagine were sprayed three times, at two-week intervals, from week 4 to week 8 in a strawberry greenhouse (Additional file 1: Figure S3). Gray mold DI from week 0 to week 4 remained relatively low (10 - 16\%) regardless of treatment. At 6 weeks, the untreated control presented a DI of $16.6 \%$; the DI in the L-asparagine-treated plot was $16 \%$, and the DI in the plot treated with L-glutamic acid was significantly lower, at $12.4 \%$. At week 8 , the DI in the untreated control increased to $34 \%$ but that in the plot sprayed with L-glutamic acid was maintained below $17 \%$ (Additional file 1: Figure S4a-c). DI values for blossom blight presented even greater differences among the treatments. At 8 weeks, $35 \%$ of flowers in the untreated control and $36 \%$ of those treated with Lasparagine developed disease symptoms, whereas fewer than $11 \%$ showed symptoms of blossom blight in the L-glutamic acid-treated plots (Additional file 1: Figure S4d-f).

\section{Glutamic acid restructured the anthosphere microbiome}


We next evaluated whether L-glutamic acid can modulate the structure of the microbial community. Sequencing analyses were performed on an Illumina MiSeq platform resulting in a total of 3,307,450 reads (Additional file 2: Table S3 and Additional file 3: Table S4) and 162 operational taxonomic units (OTUs) in the strawberry flower. Microbial diversity over 8 weeks in the untreated control did not vary significantly, whereas flowers treated with L-asparagine showed increased diversity and those sprayed with L-glutamic acid had significantly lower alpha diversity at 6 and 8 weeks (Fig. 2a and Additional file 1: Figure $S 5 a, b)$. We then used the Silva database to identify community members responsible for the shift in overall community structure. The heatmap and tree present the relative abundance of the most common OTUs (Fig. 2b). Enterobacteriaceae from weeks 2-8 had high relative abundance in the untreated control $(93 \%, 92 \%, 94 \%$, and $75 \%)$, in the L-asparagine treatment $(96 \%, 81 \%, 56 \%$, and $94 \%)$, and from weeks $2-4$, in the L-glutamic acid treatment (99.8\%, and 73.54\%). The Pseudomonadaceae had the second most abundant OTUs followed by Moraxellaceae (Fig. 2b,c and Additional file 1: Figure S5c). Enrichment of Streptomycetaceae occurred only in the L-glutamic acid treatment during weeks 6 and 8 , accounting for $99.98 \%$ and $99.99 \%$ of the community. These results are indicated by a change in the color of the heatmap from purple to yellow (Fig. 2b). Compared to the relative abundance of OTUs calculated as $\log 2$ ratios in Metacoder, Streptomycetaceae had a log2 ratio value of 3 only upon treatment with L-glutamic acid (Fig. 3a and Additional file 1: Figure S6).

The effect of the amino acids on the structure of the microbial community and suppression of plant diseases was analyzed with principal coordinate analysis (PCoA, beta diversity), non-metric multidimensional scaling (NMDS, Bray-Curtis distance method), and 3D plots of the disease incidence enrichment of the core microbe. PCoA data clearly distinguished groups, one that consisted of the untreated control and the L-asparagine treated samples (weeks 2 and 4) and the other, comprised of Lglutamic acid-treated flowers (weeks 6 and 8) (Fig. 2d). At the OTU level, PCoA analysis presented 11 OTUs with sequence identity to S. globisporus SP6C4 of greater than $98 \%$. The microbial communities of L-glutamic acid-treated flower samples (weeks 6 and 8) were also clearly distinguished (Fig. 2e). Anthosphere microbial community structures were affected by the occurrence of gray mold and blossom blight (Fig. 3b). The dispersion in NMDS indicated that microbial community structure was co-related with patterns of disease occurrence, and especially that occurrence was suppressed by treatment with Lglutamic acid. A 3D plot with three vectors and colored circles indicating the abundance of Streptomyces OTUs showed that the population of the core microbe represented more than $90 \%$ of the microbial community in L-glutamic acid-treated samples on weeks 6 and 8 (Fig. 3c). The population of SP6C4 was determined by qPCR with primers for the SP6C4-specific lanM lantipeptide biosynthesis gene [39]. On flowers sprayed with L-glutamic acid, the density of SP6C4 was greater than $10^{5} \mathrm{copy} / \mathrm{g}$ of flower, but lanM gene copies at 8 weeks on the untreated control and those sprayed with L-asparagine had fewer than $10^{4} \mathrm{copy} / \mathrm{g}$ of flower (Additional file 1: Figure S4g). These results were transformed as a bubble plot that verified that L-glutamic acid increased the population size of strain SP6C4 on strawberry flowers and was responsible for the low disease incidence but high lanM copy number from week 4 to week 8 compared to the untreated and L-asparagine controls (Additional file 1: Figure S4h). We also generated a PICRUSt2 profile of the metabolic pathways present in the microbiome community of treated flowers by 
using the KEGG database. The results showed that treatment with L-glutamic acid enhanced the abundance of Streptomyces pathways such as for biosynthesis of the type II polyketide backbone, sesquiterpenoids, neomycin, nonribosomal peptide siderophore, degradation of glycosaminoglycan and glycan, metabolism of glutamic acid, glutamatergic synapse, and limonene and pinene pathways (Fig. 3d-f and Additional file 1: Figure S7).

\section{Effect of glutamic acid on soil-borne disease}

The anthosphere has a very simple microbiome with only a few species in the community. To extend our results to a more complex microbiome, we tested the effect of glutamic acid against Fusarium oxysporum f. sp. lycopersici (FOL), the causal pathogen of Fusarium wilt disease of tomato. To evaluate whether SP6C4 and L-glutamic acid could influence the occurrence of this soil-borne disease, we established seven experimental treatments: untreated control, S. globisporus SP6C4, L-glutamic acid, FOL, SP6C4+FOL, L-glutamic acid+FOL and SP6C4+L-glutamic acid+FOL. Disease severity was evaluated seven weeks later on a scale of 0-5 (Additional file 1: Figure S8a-c). Plants treated with FOL alone presented severe disease symptoms at week 6 and all of them were dead at 7 weeks, but the other plants had disease indices of less than 2 even at 7 weeks (Additional file 1: Figure S8c).

qRT-PCR of the lanM gene in the tomato rhizosphere revealed that plants treated with SP6C4 or even Lglutamic acid alone had more than $10^{6}$ lanM gene copies per $100 \mathrm{ng}$ of soil DNA regardless of the presence of the pathogen. However, the untreated control and FOL only-treated plants had fewer than $10^{2}$ lanM gene copies, the background level (Additional file 1: Figure S8d). Taken together, the results showed that SP6C4 or L-glutamic acid successfully suppressed Fusarium wilt disease in tomato and enhanced the population density of microbes carrying the lanM gene in the rhizosphere. Additionally, at 7 weeks, both shoot length and shoot weight were significantly reduced by treatment with $\mathrm{FOL}$, but the damage was lessened by strain SP6C4 or L-glutamic acid (Additional file 1: Figure S8e,f).

\section{Rhizobiome composition was shifted by glutamic acid}

To investigate changes in the microbial community structure over time, tomato rhizosphere samples were collected 1, 3, 7, and 10 weeks after treatment except for the FOL only treated samples, none of which survived for 10 weeks. Total sequencing read numbers were 5,863,545 (Additional file 2: Table 55 and Additional file 4: Table S6) and the number of OTUs counted was 3,247. All sequences were compared with taxa in the Greengenes database at a similarity cut-off value of $\leq 98 \%$, and the top 10 OTUs present in greatest relative abundance were visualized at the phylum level (Additional file 1: Figure S9a). Proteobacteria, Actinobacteria, Firmicutes and Bacteroidetes represented more than $5 \%$ of the community. Heatmap analysis revealed changes in the rhizosphere microbial community structure, which was divided into three distinguishable clusters (Fig. 4a). The first cluster was enriched in Bacillaceae by treatment with strain SP6C4 or SP6C4+FOL (Group I; GR I); treatment with L-glutamic acid led to enrichment of Burkholderiaceae (Group II; GR II); and the third cluster included unenriched members of the 
community (Fig. 4a). Separation of L-glutamic acid and SP6C4-enriched taxa from other members of the community was visualized in an NMDS plot (Additional file 1: Figure S9b).

Co-occurrence patterns and relationships within the tomato rhizosphere microbiome among the six different treatments described above were analyzed by using Spearman's algorithm ( $R$ version 3.4.4). to create a rank of co-occurrence network pattern (Spearman's $\rho>0.8$ ) that represented either positive or negative relationships among the community members. Streptomycetaceae, Burkholderiaceae and Bacillaceae were selected as keystone taxa in the positive relationship. In the negative clusters, Caulobacteraceae, Chitinophagaceae, Devosiaceae, Rhizobiaceae and Xanthobacteraceae were identified as important taxa (Additional file 1: Figure S10). Based on the network results, we analyzed the abundance of SP6C4 in both the positive and the negative clusters. At week 3 before inoculation with FOL, communities of the untreated control and those after treatment with FOL had more negative clusters than positive relationships but the finding was not significant (Fig. $4 \mathrm{~b}$ ). These results indicated a limitation to microbial composition analysis with only two clusters. Therefore, we also analyzed the relative abundance (RA) of the keystone taxa in both positive (Streptomycetaceae, Bacillaceae, and Burkholderiaceae) and negative (Caulobacteraceae, and Chitinophagaceae) clusters. Before treatment with FOL, Streptomycetaceae were present at 40\% RA in the FOL+SP6C4 treatment. The RA of Bacillaceae was $60 \%$ in the SP6C4 treated rhizosphere and that of Burkholderiaceae was the greatest $(60 \%)$ in the rhizosphere of L-glutamic acid-treated plants. Interestingly, in the untreated control plants, keystone taxa in the negative clusters were the most abundant microbes (Caulobacteraceae, $60 \%$ and Chitinophagaceae, 45\%) (Fig. 4c). Taken together, the microbial community structure in the tomato rhizosphere was affected by introduction of strain SP6C4 or L-glutamic acid. The introduction of the core microbe, SP6C4 enriched Bacillaceae, and drenching with L-glutamic acid increased the density of Burkholderiaceae in the rhizosphere. The findings indicated that SP6C4 and L-glutamic acid have different modulating effects on the rhizosphere microbiome community. The disease indices after FOL treatment alone reached 3; plants treated with FOL+L-glutamic acid+SP6C4 had a disease index of 2, and plants treated with FOL+antibiotics developed a disease index of 1.6. However, disease development in plants treated with L-glutamic acid+FOL, L-glutamic acid alone, or antibiotics alone did not differ significantly from the untreated plants (Additional file 1: Figure S11).

\section{Glutamic acid does not activate ISR in strawberry or tomato}

We wondered whether L-glutamic acid inhibited disease occurrence by activating the plant's induced systemic resistance (ISR) response in either strawberry or tomato. For strawberry, a total of 7 treatments was examined including an untreated control, pathogen (Botrytis cinerea) only, L-glutamic acid, antibiotics, L-glutamic acid with antibiotics, antibiotics with the pathogen, and L-glutamic acid, antibiotics, and pathogen (Fig. 5a). The pathogen only treatment showed 100\% disease incidence, but with L-glutamic acid and the pathogen, infection was less than 50\% (Additional file 1: Figure S12a,b). As expected, the population of the SP6C4 was increased significantly in treatments with L-glutamic acid only and L-glutamic acid with the pathogen ( $10^{5}$ lanM gene copy per $\mathrm{g}$ of flower) (Fig. $5 \mathrm{~b}$ ). The influence of Lglutamic acid on activation of plant ISR genes was evaluated by qRT-PCR. The jasmonic acid (JA) related 
genes $L O X 2$ and PR10 were not expressed in the untreated control or in treatments with L-glutamic acid and L-glutamic acid with the pathogen. However, LOX2 and PR10 were highly expressed in the pathogen only, antibiotics with the pathogen, and L-glutamic acid plus antibiotics and pathogen treatments (Fig. 5d and Additional file 1: Figure S13a). Expression of salicylic acid (SA) related genes (PR1 and PR2) showed a pattern similar to that of JA related gene expression; the pathogen, antibiotics with pathogen, and Lglutamic acid, antibiotics and pathogen treatments triggered expression of the $P R 1$ and $P R 2$ genes. These SA related genes were not expressed in the untreated control or in treatments with L-glutamic acid or L-glutamic acid with pathogen (Fig. 5e and Additional file 1: Figure S13a).

The population size of the SP6C4 as measured by qRT-PCR with lanM in the rhizosphere soil of the Lglutamic acid only and L-glutamic acid+FOL-treated plants was $10^{5}$ gene copies/g of rhizosphere soil. However, the untreated control, FOL, antibiotics, antibiotics+FOL, and L-glutamic acid+antibiotic+FOL treated plants showed significantly lower density of the core microbe, with only $10^{3} / a n M$ gene copies $/ \mathrm{g}$ of rhizosphere soil (Fig. 5c). Collectively, we interpret these results to indicate that glutamic acid increased density of Streptomyces, the functional core microbe, which suppressed the fungal pathogen. In tomato, ISR and PAMP-related gene expression was evaluated relative to that of the housekeeping gene glyceraldehyde-3-phosphate dehydrogenase (GAPDH). JA related genes (Tomlex A, Tomlex C and PINII) were expressed after treatment of the seedlings with FOL, antibiotics, antibiotics+FOL and L-glutamic acid+ antibiotics+FOL, but not in the untreated control or after treatment with L-glutamic acid, and Lglutamic acid+FOL (Fig. $5 f$ and Additional file 1: Figure S13b). Among SA-related genes (PR1b1, PR-P2 and $S A M T$ ), only PR1b1 was expressed, and only in plants treated with FOL, antibiotics, FOL+antibiotics, and FOL+L-glutamic acid+antibiotics but not in the untreated control or in plants treated with L-glutamic acid or L-glutamic acid+FOL (Fig. $5 \mathrm{~g}$ and Additional file 1: Figure S13c). The ET related gene ERF1 was not expressed in any of the treatments (Additional file 1: Figure S13d) and the PAMP response gene Pti5 showed response patterns similar to those of the JA related genes (Additional file 1: Figure S13e). Taken together, these findings suggest first, that plant ISR was not activated by L-glutamic acid; second, that Lglutamic acid reconfigured the anthosphere and rhizosphere microbiome communities; and third, that the engineered microbiomes protected the plant from the pathogens.

\section{Discussion}

That microbes from the soil play a critical role in plant health has been known and investigated for well over century [40], but it is only recently that the assemblage of the microbiota selected by the plant from the environment (i.e., the microbiome), together with the the host, has been recognized as an ecological unit, the 'holobiont' $[41,42]$. Collectively, the microbiome extends the genetic and physiological capacity of the host, contributing to its growth and well-being by providing ecological services and protection from biotic and abiotic stresses.

Much as the animal gut microbiome can be influenced by probiotics, diet [32, 43,44] or prebiotics [45-47] with the potential to engineer its composition or activity, so also is the structure of plant microbiome community responsive to the types and amounts of metabolites present in plant exudates secreted into 
the rhizosphere $[48,49]$. The plant developmental stage and genotype influence the microbiome community structure as well as the root architecture and chemistry, which have a significant impact on microbiome composition [50]. The quality and quantity of root exudate directly impacts rhizosphere microbiome assembly.

We have shown here that glutamic acid, either secreted by the plant or added exogenously, functions as a prebiotic and plays a key tool in a bottom-up model of plant microbiome engineering $[25,51]$ built around Streptomyces as a core member of the microbial community. In both the anthosphere of strawberry, with its very simple microbiome, and in the complex rhizosphere microbiome of tomato, glutamic acid initiated a cascade resulting in reconfiguration of the microbiome and enrichment of Streptomyces in the community. Of note is that as a consequence of this process, both foliar and root pathogens were controlled. on unrelated plant species. It is not uncommon for chemicals applied to plants to induce systemic resistance, but with glutamic acid the effect was not due to the induction of resistance through either the ethylene/jasmonic acid or the salicylic acid pathway. We were surprised by the extent of modification of the two microbiomes by the addition of a single chemical. However, some substrates are preferentially metabolized by microbes [45] and can selectively engineer the composition or activity of entire microbial communities, influencing the health of the host [46,52], much as when diet affects the composition of the gut microbiome $[29,32,44,53]$. Our results indicate that glutamic acid functions directly as a link to the microbiome; it directly affected the microbiome community structure and engineered it to suppress disease incidence. Moreover, the fact that glutamic acid did not activate host plant resistance mechanisms suggests that it may provide insight into evolutionary and functional relationships between the plant and its microbiome. Glutamic acid, in particular, is metabolized by Streptomyces as sole source of carbon and nitrogen, favoring vigorous growth [54], which may help to explain its effect on the plant-associated communities we observed in this study. How did the relationship of the host and the microbiome evolve? Perhaps the answer can be found in the biological function of the microbiome. Plants are constantly exposed to changing environmental forces that also act to shape the microbiome, but at the same time, the microbiome community structure is flexible and capable of buffering the impact of the environment on the host.

In our experimental system, the community structure and abundance of the phytobiome were influenced by the amount of glutamic acid available via exudates or by exogenousdelivery. Given that glutamic acid is naturally present in host exudates, it would seem that plants already have the potential to engineer protective microbiomes themselves. Thus, with better understanding of the relationship between plant exudates and microbiome assembly, it may be possible to develop crops that can recruit their own microbiota to better withstand pathogen attack.

\section{Conclusions}

While our results indicate clearly that glutamic acid is a powerful mediator of the structure of the plantassociated microbiome, much remains to be determined about how it interfaces with the complex metabolic and signaling exchanges among microbes and their plant hosts. There has been considerable 
progress in recent years towards elucidating the structure and function of plant-associated microbial communities, but new approaches are needed to reveal how the composition of the community and its function are controlled. Based on the results of this study, we propose that glutamic acid configures the microbial community and modulates the composition of a core microbiome that benefits the plant by influencing such agronomic metrics as crop quality and yield.

\section{Methods}

\section{Strawberry sampling}

Strawberry plants (cv. Meahyang) were cultivated in a high-bed greenhouse in Jinju, Republic of Korea $\left(34^{\circ} 59^{\prime} 35.2^{\prime \prime} \mathrm{N} 128^{\circ} 02^{\prime} 50.3^{\prime \prime} \mathrm{E}\right)$. Strawberry flowers ( $n=15-20$ per sample) were selected at random for analysis of nitrogen, carbon and organic acid concentrations at two-week intervals from September, 2013 to January, 2014.

\section{Chemicals and reagents for strawberry flower exudate profile analysis}

As internal standards, 23 amino acids (AA), 17 organic acids (OA), norvaline, 3,4-dimethoxybenzoic acid, ethyl chloroformate (ECF) and methoxyamine hydrochloride were purchased from Sigma-Aldrich (St. Louis, MO, USA). N-Methyl-N-(tert-butyldimethylsilyl) trifluoroacetamide (MTBSTFA) was obtained from Pierce (Rockford, IL, USA). HPLC grade toluene, diethyl ether, ethyl acetate, and dichloromethane were purchased from Kanto Chemical (Tokyo, Japan). Hydrophilic polyvinylidene difluoride (PVDF) membrane filters (Millipore Durapore ${ }^{\circledR}, 0.45 \mu \mathrm{m}, 25 \mathrm{~mm}$ diameter) were purchased from Millipore Inc. (Darmstadt, Germany). All other chemicals were of analytical grade and were used as received.

\section{Strawberry petal and ovary samples for exudate analysis}

For amino acid (AA) and organic acid (OA) analysis, $100 \mu \mathrm{g}$ of freeze-dried petal or ovary was mixed with $10 \mathrm{~mL}$ distilled water, sonicated for $30 \mathrm{~min}$, and filtered through a hydrophilic PVDF membrane (Millipore Durapore $\AA, 0.45 \mu \mathrm{m}, 25 \mathrm{~mm}$ diameter) by centrifugation at $1,077 \mathrm{~g}$ for $5 \mathrm{~min}$. AAs and $0 A s$ in the samples were analyzed by gas chromatography-mass spectrometry (GC-MS) using an Agilent $6890 \mathrm{~N}$ gas chromatograph interfaced with an Agilent 5975B mass-selective detector (70 eV, electron impact mode) equipped with an Ultra-2 (5\% phenyl-95\% methylpolysiloxane bonded phase; $25 \mathrm{~m}^{\prime} 0.20 \mathrm{~mm}$ i.d., $0.11 \mu \mathrm{m}$ film thickness) cross-linked capillary column (Agilent Technologies, Palo Alto, CA, USA). The temperatures of the injector, interface, and ion source were 260,300 , and $230^{\circ} \mathrm{C}$, respectively. Helium was used as the carrier gas at a flow rate of $0.5 \mathrm{~mL} \mathrm{~min}^{-1}$ in the constant flow mode. Samples were loaded in the split-injection mode (10:1); the oven temperature for AA profiling was initially set at $120^{\circ} \mathrm{C}(2 \mathrm{~min})$, rose first to $240^{\circ} \mathrm{C}$ at $5^{\circ} \mathrm{C} \mathrm{min}-1$ then to $300^{\circ} \mathrm{C}(3 \mathrm{~min})$ at $30^{\circ} \mathrm{C} \mathrm{min}^{-1}$. The oven temperature for $\mathrm{OA}$ analysis was initially $100^{\circ} \mathrm{C}(2 \mathrm{~min})$, rose first to $240^{\circ} \mathrm{C}$ at $5^{\circ} \mathrm{C} \mathrm{min}{ }^{-1}$, and then to $300^{\circ} \mathrm{C}(5 \mathrm{~min})$ at $30^{\circ} \mathrm{C} \mathrm{min}^{-1}$. The mass range scanned was 50-600 $\mathrm{u}$ at a rate of 0.99 scans per sec. In the selected ion monitoring (SIM) mode, three characteristic ions for each $A A$ and $O A$ were used for peak identification and quantification. 
AA analysis was performed by using a previous method [57, 58]. Briefly, $0.5 \mathrm{ml}$ aliquots from the petal or ovary were adjusted to $\mathrm{pH} \geq 12$ with $5.0 \mathrm{M} \mathrm{NaOH}$ and diluted with $0.5 \mathrm{~mL}$ distilled water and $0.1 \mathrm{mg}$ of norvaline as internal standard. A two-phase ethoxycarbonylation (EOC) reaction was immediately conducted in the aqueous phase. The reaction mixture was then acidified $(\mathrm{pH} \leq 2.0)$ with $10.0 \%$ sulfuric acid, saturated with sodium chloride, and subjected to extraction sequentially with diethyl ether $(3.0 \mathrm{~mL})$ and ethyl acetate $(2.0 \mathrm{~mL})$. The combined extracts were evaporated to dryness under a gentle stream of nitrogen $\left(40^{\circ} \mathrm{C}\right)$. The residue was reacted $\left(60^{\circ} \mathrm{C}, 30 \mathrm{~min}\right)$ with MTBSTFA $(20 \mu \mathrm{L})$ and toluene $(20 \mu \mathrm{L})$ for GC-SIM-MS analysis.

For $\mathrm{OA}$ profiling, $0.5 \mathrm{~mL}$ of the petal or ovary extract was adjusted to $\mathrm{pH} \geq 12$ with $5.0 \mathrm{M} \mathrm{NaOH}$ and 0.1 $\mu \mathrm{g}$ of 3,4-dimethoxybenzoic acid was added as an internal standard. The carbonyl groups were converted to methoxime $(\mathrm{MO})$ derivatives by reaction with methoxyamine hydrochloride $(1.0 \mathrm{mg})$ at $60^{\circ} \mathrm{C}$ for 30 min. The reaction mixture was then acidified $(\mathrm{pH} \leq 2.0)$ with $10.0 \%$ sulfuric acid, saturated with sodium chloride, and subjected to extraction sequentially with diethyl ether $(3.0 \mathrm{~mL})$ and ethyl acetate $(2.0 \mathrm{~mL})$. After addition of trimethylamine $(5 \mu \mathrm{L})$, the combined extracts were evaporated to dryness under a gentle stream of nitrogen at $40^{\circ} \mathrm{C}$. The residue was reacted $\left(60^{\circ} \mathrm{C}\right.$ for $\left.30 \mathrm{~min}\right)$ with MTBSTFA ( $N$-tertbutyldimethysily- $N$-methytrifluoroacetamide, $20 \mu \mathrm{L})$ and toluene $(10 \mu \mathrm{L})$ for $\mathrm{GC}-\mathrm{SIM}-\mathrm{MS}$ analysis. The concentrations of 23 AAs and 17 OAs in each petal or ovary sample were determined based on a calibration curve derived from the corresponding mean values of a control group.

\section{Carbon source analysis of strawberry flowers}

Soluble sugars including glucose, fructose, maltose, raffinose, and sucrose were analyzed as described by Yoon et al. [59]. Flower samples $(0.1 \mathrm{~g})$ were homogenized in glass tubes with $6 \mathrm{~mL}$ of HPLC grade ethanol (80\%), and incubated at $65^{\circ} \mathrm{C}$ for $20 \mathrm{~min}$. The supernatant fraction was collected after centrifugation at $3500 \mathrm{rpm}$ for $10 \mathrm{~min}$ and the process was carried out three times. The pooled extracts were filtered through a $0.45 \mu \mathrm{m}$ syringe filter and then concentrated under nitrogen. Sugar content was determined with an Agilent 1100 high performance liquid chromatograph (HPLC) with a refractive index detector (Agilent Tech., Germany) after baseline resolution of a column (ZORBX, 4.6 X $150 \mathrm{~mm}, 5 \mathrm{~mm}$ particle size, Agilent Tech) at a flow rate of $1 \mathrm{~mL} / \mathrm{min}$. Samples $(20 \mu \mathrm{L})$ were injected with $75 \%$ acetonitrile and sugar content was calculated with an internal standard.

\section{Carbon and nitrogen source utilization}

Streptomyces globisporus SP6C4 was grown on MS medium (20 g mannitol, $20 \mathrm{~g}$ soya, $20 \mathrm{~g}$ agar per $\mathrm{L}$ ) at $30^{\circ} \mathrm{C}$ for 5 days. A single colony was streaked on a fresh plate and mature spores were recovered after 10 days with a sterilized cotton ball and $1 \mathrm{~mL}$ of $\mathrm{ddH}_{2} \mathrm{O}$. After filtration, the spore concentration was adjusted to an $\mathrm{OD}_{600} \mathrm{~nm}$ of 2.0, mixed with $0.2 \%$ carrageenan stock solution, and incubated, $100 \mu \mathrm{L}$ per well, in sealed plates (PM1-carbon sources and PM3B-nitrogen sources) (Biolog, Bremen, Germany) at $28^{\circ} \mathrm{C}$ for 2 days. Then $10 \mu \mathrm{L}$ of Biolog redox dye was added to each well and the intensity of color change 
was monitored at $\mathrm{OD}_{590} \mathrm{~nm}$ every 30 min for 3 hours with a Synergy $\mathrm{H} 1$ Hybrid Multi-Mode microplate reader (BioTek, Winooski, VT, US) [60].

\section{Disease incidence of gray mold and blossom blight and qPCR of lanM}

The incidence of gray mold and blossom blight caused by Botrytis cinerea and Cladosporium spp., respectively, was expressed as the percentage of infected plants in a greenhouse of 9 plots, each with 100 strawberry plants. Early symptoms of gray mold included brown spots on flower petals and were followed by gray conidia covering flowers and fruits [61]. Blossom blight appeared as gray fungal growth on flower pistils and stamens and as infected, malformed or misshapen fruits [62]. Differences in disease incidence among an untreated control and treatments with $2 \%$ glutamic acid or L-asparagine were analyzed by followed by the paired ANOVA and compared for mean separation with the untreated plots with Tukey's HSD $(P=0.05)$.

To determine whether the population size of the core microbe S. globisporus SP6C4 increased in response to the amino acid treatments, microbial DNA from the flower anthosphere was extracted and the SP6C4-specific marker gene lanM was quantified by qPCR with $\mathrm{F}$ and $\mathrm{R}$ primers as described by Kim et al. [39]. qPCR reactions in SYBR Green ${ }^{\circledR}$ TOYOBO master mix included denaturation at $98^{\circ} \mathrm{C}$ for 5 min followed by 40 cycles of denaturation at $98^{\circ} \mathrm{C}$ for $30 \mathrm{sec}$, annealing at $59^{\circ} \mathrm{C}$ for $30 \mathrm{sec}$ and elongation at $72^{\circ} \mathrm{C}$ for $45 \mathrm{sec}$ with a CFX Connect ${ }^{\mathrm{TM}}$ Optics Module Real-Time PCR System (Bio-Rad, Hercules, CA, USA).

\section{Microbial community analysis of strawberry flowers}

Flowers were collected from a $660 \mathrm{~m}^{2}$ greenhouse with 15 plots of $1.5 \times 3 \mathrm{~m}^{2}$, each with 100 strawberry plants. Each of three treatments (untreated control, L-glutamic acid or L-asparagine at a final concentration of $2 \%, \mathrm{pH} 6.5$ ) in five randomly arranged replicate plots was sprayed for 1 min per plot (Sprayer: HP-2010, Korea, $1.5 \mathrm{~L}$ discharge capacity $\mathrm{min}^{-1}$ ) at two-week intervals during January and February, 2018. Five samples per plot, each with 3 to 5 flowers, were collected into 50-mL Falcon tubes at two-week intervals from December, 2017 through February, 2018, chilled on ice to preserve microbial communities, and transported to the laboratory for sequence analysis.

Flower samples $(1 \mathrm{~g})$ were transferred to fresh tubes with $30 \mathrm{~mL}$ of cold $1 \mathrm{X}$ PBS buffer (10X PBS: $8 \mathrm{~g}$ of $\mathrm{NaCl}, 0.2 \mathrm{~g}$ of KCl, $1.44 \mathrm{~g}$ of $\mathrm{Na}_{2} \mathrm{HPO}_{4}, 0.24 \mathrm{~g}$ of $\mathrm{KH}_{2} \mathrm{PO}_{4}$ per $\mathrm{L}$, $\mathrm{pH}$ of 7.4 ) and sonicated at $35 \mathrm{MHz}$ for 15 sec to detach unwanted dust. The upper portion of the supernatant solution was gently removed by pipetting and this rinsing step was repeated twice. Finally, the supernatant was removed by centrifugation at 4,000 rpm for $20 \mathrm{~min}$, the pellet was suspended in $5 \mathrm{~mL}$ PBS., and total DNA was purified from $500 \mu \mathrm{L}$ with a Fast DNA ${ }^{\mathrm{TM}}$ Spin Kit for Soil DNA extraction (MP Biomedicals, Irvine, CA, US) according to manufacturer's instructions, PCR reactions were conducted with $100 \mathrm{ng}$ of the purified DNA and primers $27 \mathrm{mF}$ (5'-gagtttgatcmtggctcag-3') and $518 \mathrm{R}$ (5'-wttaccgcggctgctgg-3') to amplify the V1-V3 region of 16S rRNA, and a library was generated with Herculasell Fusion DNA Polymerase and a Nextera XT Index Kit v2 (Illumina, San Diego, CA USA). Paired-end sequencing was carried out at Microgen (Seoul, Korea) 
on an Illumina MiSeq platform (Illumina Inc., San Diego, CA, USA). Sequences of $300 \mathrm{bp}$ or more and nucleotide quality scores $>30$ were recovered after screening with the DADA2 package in $\mathrm{R}$ (version 1.14). The Silva database (http://www.arb-silva.de/) for OTU clustering was used to assign taxonomy of OTUs and alpha diversity with a taxonomic classification similarity cutoff of $\leq 97 \%$, principal coordinate analysis (PCOA) and nonmetric multidimensional scaling (NMDS), and OTU bars were visualized with ggplot2 ( $R$, version 3.4.4). Superheat (version 0.1.0) was used to generate heatmaps and OTU abundance was calculated with Metacoder (version 0.3.3) and PICRUSt2 (version 2.1.4 beta). Accession numbers for all sequencing data were recorded in GenBank (Additional file 2: Table S7).

\section{Effect on gray mold incidence of antibiotic and amino acid treatments to engineer the microbiome community}

Strawberry seedlings (cv. Meahyang) were stored at $-2^{\circ} \mathrm{C}$ for one month for vernalization and then transferred to plastic pots (10 cm diameter). Twelve days after planting, each plant had 5-7 flowers. Then, L-glutamic acid $(5 \mu \mathrm{g} / \mathrm{mL})$ and the antibiotics erythromycin and clindamycin $(10 \mu \mathrm{g} / \mathrm{mL}$ each, to inhibit Streptomyces, Research Products International, Mt. Prospect, IL, USA) [63-66] were applied with a sprayer. Three days later, freshly grown conidia of $B$. cinerea were collected with a cheese cloth filter and sprayed at $10^{5} \mathrm{cfu} / \mathrm{mL}$ on the flowers. The seven treatments of 5 plants each included an untreated control, pathogen only (B. cinerea), L-glutamic acid only, antibiotics only, Glu + pathogen, antibiotics + pathogen, and Glu + antibiotics + pathogen. All plants were maintained in a growth chamber with a daytime temperature of $25^{\circ} \mathrm{C} \pm 3$; a nighttime temperature of $15^{\circ} \mathrm{C} \pm 3$; and relative humidity of $85 \%$. Seven weeks later, disease incidence was scored on 30 flowers (10 independent replicates) and the lanM gene was quantified on $1 \mathrm{~g}$ of flowers ( $n=3$ to 5 flowers).

For qRT-PCR, RNA was extracted from the flower samples using the plant RNA single-step extraction method $[67,68]$. Each sample $(100 \pm 0.5 \mathrm{mg})$ was added to a $2-\mathrm{mL}$ tube of lysing matrix E (Fast DNA ${ }^{\mathrm{TM}}$ Spin Kit for Soil DNA extraction, MP Biomedicals) with $1 \mathrm{~mL}$ of TRIzol ${ }^{\circledR}$ Reagent (Invitrogen) and homogenized with a FastPrep-24 instrument (MP Biomedicals) for 1 min. Four jasmonic acid (JA-) and salicylic acid (SA-) related ISR marker genes with the glyceraldehyde-3-phosphate dehydrogenase (GAPDH) gene as a standard housekeeping gene [69-71] were detected by qRT-PCR. For reactions, $1 \mu \mathrm{g}$ of RNA was used as template to synthesize cDNA with a TOYOBO ReverTra Ace ${ }^{\circledR}$ qPCR RT Kit (Toyobo Co., Osaka, Japan). After cDNA synthesis, $20 \mu \mathrm{L}$ of the products were diluted 1:5 with RNase-free water and 4 $\mathrm{mL}$ was mixed with $25 \mu \mathrm{L}$ of SYBR Green ${ }^{\circledR}$ TOYOBO master mix, $1 \mu \mathrm{L}$ of each forward and reverse primer, and $16 \mu \mathrm{L}$ of HPLC grade $\mathrm{H}_{2} \mathrm{O}$. The PCR program included an initial denaturation at $98^{\circ} \mathrm{C}$ for $1 \mathrm{~min}$, followed by denaturation at $98^{\circ} \mathrm{C}$ for $30 \mathrm{sec}$, annealing as indicated in Additional file 2: Table S8 and $60^{\circ} \mathrm{C}$ for $30 \mathrm{sec}$, and elongation at $72^{\circ} \mathrm{C}$ for $45 \mathrm{sec}$ for 40 cycles. qRT-PCR was performed with a CFX Connect $^{\text {TM }}$ Optics Module Real-Time PCR System (Bio-Rad, USA). All primer information is presented in Additional file 2: Table S8. The experiment was conducted with three technical replications.

\section{Fusarium wilt disease suppression on tomato by strain SP6C4 and with L-glutamic acid}


For assays of Fusarium wilt disease control, tomato plants (cv. Heinze) were maintained in a plant growth chamber for 4 weeks. Conditions included a $16 \mathrm{hr}$ day cycle at $27 \pm 2^{\circ} \mathrm{C}$ and an $8 \mathrm{hr}$ night cycle at $20 \pm 2^{\circ} \mathrm{C}$, both at $80 \%$ relative humidity. Seed was sterilized in $1.5 \% \mathrm{NaOCl}$ for 30 min with gentle shaking and washed 3 times with $\mathrm{dd}_{2} \mathrm{O}$. The seeds were germinated on damp cotton in a Petri dish (9-cm, diam.) for 3 days at $4^{\circ} \mathrm{C}$ and then transferred to plastic pots (10-cm, diam.) with autoclaved nursery soil. After 5 days' germination, $10 \mathrm{~mL}$ of L-glutamic acid $(5 \mu \mathrm{g} / \mathrm{mL})$ and $10^{5} \mathrm{cfu} / \mathrm{mL}$ of Fusarium oxysporum $\mathrm{f}$. sp. lycopersici (FOL) chlamydospores $(10 \mathrm{~mL})$ were drenched into the soil. Images of stem and leaf growth were captured two weeks later, at the early vegetative stage and at six weeks, (late vegetative stage). Shoot length, shoot fresh weight and disease indexes were scored weekly at 6 levels: $(0$, no symptoms; 1 , slight yellowing of the lower leaves; 2 , moderate yellowing of the entire plant; 3 , wilted plant; 4 , plants severely stunted or browning; 5 , plants dead). All treatments had 3 biological replications and the mean \pm $\mathrm{SE}$ of the results was calculated by one-way ANOVA in R (version 3.4.4.).

For sequencing analysis of rhizosphere populations, growth conditions of tomato plants were as described above. Tomato seedlings were grown in sterilized soil for 10 weeks and then $10 \mathrm{~mL}$ of Lglutamic acid $(5 \mu \mathrm{g} / \mathrm{mL})$ was applied by drenching 3 times at 3-day intervals between weeks 2 and 3 . Strain SP6C4 was cultured in TSB broth containing $20 \%$ sucrose and $1 \%$ mannitol for sporulation. The harvested spores were washed four times with deionized, distilled $\mathrm{H}_{2} \mathrm{O}$ and the pellet was suspended in $50 \mathrm{~mL}\left(\mathrm{OD}_{595 \mathrm{~nm}} 0.7 \pm 0.05\right)$ of $0.1 \%$ Hoagland solution containing $0.1 \%$ methylcellulose $(\mathrm{MC})$ and inoculated into the soil four weeks after planting. Seven days later, FOL chlamydospore stock $\left(10^{5}\right.$ $\mathrm{cfu} / \mathrm{mL}$ ) was inoculated into the soil. The disease index was scored every 5 days for 20 days using the five-grade scale above. At 10 weeks, the rhizosphere soil of 3 replicate plants was pooled for DNA extraction and sequencing. The seven treatments included an untreated control, FOL alone, L-glutamic acid (Glu) alone, SP6C4 alone, FOL + Glu, FOL + SP6C4, and FOL + Glu + SP6C4. Rhizosphere soil (0.5 g) was added to lysing matrix $E$ and DNA was extracted using a FastDNA Spin Kit (MP Bio). The DNA was suspended in $50 \mathrm{~mL}$ of DES buffer and the tubes were stored at $-20^{\circ} \mathrm{C}$ for sequencing and lanM gene qRT-PCR. For sequencing, $200 \mathrm{ng}$ of DNA was precipitated with ethanol and the V4 region of 16S rRNA was amplified with primers 515F forward (5'- gtgycagcmgccgcggtaa-3') and 806R reverse (5'-

ggactacnvgggtwtctaat-3'). PCR products were subjected to Illumina MiSeq 250-bp paired-end sequencing at Macrogen (Daejeon, Korea). For $16 \mathrm{~S}$ rRNA gene-based bacterial community analysis, the data were trimmed of low quality reads ( $<30$ minimum quality score) and primer sequences by using the DADA2 package in $\mathrm{R}$ (version 1.14), quality filtered, and processed according to Greengenes data base (https://greengenes.secondgenome.com) with a taxonomic classification similarity cutoff of $\leq 98 \%$. The most dominant OTUs were shown by NMDS and OTU bars using ggplot2 in the R package ( $R$, version 3.4.4). Other visualizations were made using superheat (version 0.1.0) for heatmaps, OTU abundance was calculated with NOI-seq (version 3.10) and co-occurrence was calculated with Spearman's method. All sequencing data and GenBank accession numbers were recorded in Additional file 2: Table S7.

Rhizosphere microbial community engineering with L-glutamic acid and suppression of Fusarium wilt disease in tomato

Page $14 / 31$ 
Seedlings of tomato (cv. Heinze) were maintained in a growth chamber under day/night conditions of 16 $\mathrm{h}$ light and $8 \mathrm{~h}$ dark. Temperature during the light cycle was $25^{\circ} \mathrm{C} \pm 2$ and was increased after inoculation of $\mathrm{FOL}$ to $28^{\circ} \mathrm{C} \pm 2$ to enhance pathogen infection. The dark phase temperature was held at $20^{\circ} \mathrm{C} \pm 2$ and humidity was no greater than $85 \%$. Seeds were sown in autoclaved nursery soil and irrigated with $0.1 \%$ Hoagland's solution. After 12 days, the seedlings were treated with a $10 \mathrm{~mL}$ mixture of L-glutamic acid (5 $\mu \mathrm{g} / \mathrm{mL}$ ) and antibiotics (erythromycin and clindamycin, each at $10 \mu \mathrm{g} / \mathrm{mL}$ ). FOL inoculation was performed with a chlamydospore stock solution $\left(10^{5} \mathrm{cfu} / \mathrm{mL}\right)$ at 15 days. At 6 weeks, the rhizosphere soil was collected to calculate lanM copy number and the expression of ISR-related genes by qRT-PCR (Additional file 2: Table S8). At the final of sampling time (week 6), the wilt disease index was determined for 5 independent plants as 6 levels: 0 , no symptoms; 1 , slight yellowing of the lower leaves; 2, moderate yellowing of the entire plant; 3 , wilted plant; 4 , plants severely stunted or browning; 5 , plants dead.

Rhizosphere samples consisting of $150 \mathrm{mg}$ of soil closely adhered to roots were added to lysing matrix $\mathrm{E}$ tube (MP biomedicals), lysed in 1-mL of TRIzol ${ }^{\circledR}$ Reagent (Invitrogen) and homogenized with a FastPrep24 kit by a RNA single-step extraction method. The extracted RNA was cleaned with a spin column (RNeasy kit, Qiagen, Hidden, Germany). Ten $\mu \mathrm{L}$ of DNase and $70 \mu \mathrm{L}$ of RDD buffer (RNeasy kit, Qiagen) were added on the column and incubated at ambient temperature for $15 \mathrm{~min}$ and then the column was washed with $350 \mu \mathrm{L}$ of RW1 buffer and $500 \mu \mathrm{L}$ of RPE buffer (RNeasy kit) at $8000 \mathrm{x} \mathrm{g}$ for $15 \mathrm{sec}$. The column was transferred to a new tube $(1.5-\mathrm{mL})$ and incubated on ice for $1 \mathrm{~min}$. For elution, $15 \mu \mathrm{L}$ of RNase-free water was added and the column was centrifuged at $8000 \mathrm{xg}$ for $1 \mathrm{~min}$. For qRT-PCR, $1 \mu \mathrm{g}$ of total RNA and oligo dT primers were used with a ReverTra Ace ${ }^{\circledR}$ qPCR RT kit (Toyobo). qRT-PCR was performed with $4 \mu \mathrm{l}$ of cDNA, $16 \mathrm{~mL}$ RNase free water, $25 \mu \mathrm{L}$ of SYBR Green ${ }^{\circledR}$ master mix (QPK-201T, Japan), and $\triangle \triangle \mathrm{Ct}$ values were calculated for JA (tomlex $A$, tomlex $C$, PINI), SA (SAMT, PR1b1, PR-P2), ET (erf) and PAMP; activated at pathogen infection (pti5)-related genes and actin and tubulin housekeeping genes [72-74]. All primer information is presented in Additional file 2: Table S8.

\section{Statistical analyses}

All data except for sequence analyses were analyzed by ANOVA and $t$-test. Comparisons were used to demonstrate differences among mean values with Tukey's HSD and graphs were visualized by ggplots version 3.0.1 and ggplot2 version 2.1.0 in the $\mathrm{R}$ software package.

\section{Declarations}

\section{Ethics approval and consent to participate}

Not applicable.

\section{Consent for publication}

Not applicable. 
Availabilityofdata and materials

Sequencing data for L-glutamic acid-treated flower samples have been deposited in GenBank under SAR accession number SRR11355399 [https://www.ncbi.nlm.nih.gov/sra/SRR11355399] and all other GenBank data in Additional file 2: Table S7. All data are available in the manuscript the supplementary materials and analyses of microbial community composition were carried out with $\mathrm{R}$ program (version 3.4.4). The source code of $R$ for data analyses is available on GitHub at https://github.com/ekfks0125/2020_Kim.git.

\section{Competing Interests}

The authors declare that they have no competing interests.

\section{Funding}

This work was supported by the National Research Foundation of Korea (NRF) grant funded by the Korea government (MSIT) (2020R1A2C2004177) and the Rural Development Administration Next-Generation BioGreen 21 Program (PJ013250). USDA is an Equal Opportunity Employer and Provider.

\section{Author Contributions}

DK, DW, LT and YK designed and developed the experiments. DK and YK performed pyrosequencing analyses. MP and YL conducted all amino acid, organic acid and sugar content analysis. DK, and YK conducted genome, bioinformatics, and statistical analyses. D.K, C.J and Y.K performed all the greenhouse work. D.K, D.W, L.T, and Y.K wrote the manuscript.

\section{Acknowledgments}

Not applicable.

\section{References}

1. del Carmen Orozco-Mosqueda M, del Carmen Rocha-Granados M, Glick BR, Santoyo G. Microbiome engineering to improve biocontrol and plant growth-promoting mechanisms. Microbiol Res. 2018;208:25-31.

2. Liu H, Macdonald CA, Cook J, Anderson IC, Singh BK. An ecological loop: Host microbiomes across multitrophic interactions. Trends in Ecol Evol. 2019;34:1118-1130.

3. Vannier N, Agler M, Hacquard S. Microbiota-mediated disease resistance in plants. PLoS Pathog. 2019;15:e1007740.

4. Rodriguez PA, Rothballer M, Chowdhury SP, Nussbaumer T, Gutjahr C, Falter-Braun P. Systems biology of plant-microbiome interactions. Molecular Plant. 2019;12:804-821. 
5. Lawson CE, Harcombe WR, Hatzenpichler R, Lindemann SR, Löffler FE, O'Malley MA, Martín HG, et al. Common principles and best practices for engineering microbiomes. Nat Rev Microbiol. 2019;17:117.

6. Kim D, Cho G, Jeon C, Weller DM, Thomashow LS, Paulitz TC, Kwak Y. A mutualistic interaction between Streptomyces bacteria, strawberry plants and pollinating bees. Nat Commun. 2019;10:1-10.

7. Nayfach S, Shi ZJ, Seshadri R, Pollard KS, Kyrpides N. New insights from uncultivated genomes of the global human gut microbiome. 2019;568:505-510.

8. Niu B, Paulson JN, Zheng X, Kolter R. Simplified and representative bacterial community of maize roots. 2017;114:E2450-E2459.

9. Hassani MA, Durán P, Hacquard S. Microbial interactions within the plant holobiont. 2018;6:58.

10. Lugtenberg B, Kamilova F. Plant-growth-promoting rhizobacteria. Annu Rev Microbiol. 2009; 63:541556.

11. Shoresh M, Harman GE, Mastouri F. Induced systemic resistance and plant responses to fungal biocontrol agents. Annu Rev Phytopathol. 2010;48:21-43.

12. Ahmad M, Nadeem SM, Zahir ZA. Plant-microbiome interactions in agroecosystem: An application. In Microbiome in Plant Health and Disease. Singapore: 2019. p. 251-291.

13. Berendsen RL, Vismans G, Yu K, Song Y, de Jonge R, Burgman WP, Burmølle M, Herschend J, Bakker PA, Pieterse CM. Disease-induced assemblage of a plant-beneficial bacterial consortium. ISME J. 2018;12:1496-1507.

14. Badri DV, Vivanco JM. Regulation and function of root exudates. Plant Cell Environ. 2009;32:666681.

15. Chaparro JM, Sheflin AM, Manter DK, Vivanco JM. Manipulating the soil microbiome to increase soil health and plant fertility. Biol Fertility Soils. 2012;48:489-499.

16. Etesami H, Beattie G. Probiotics and Plant Health. Springer. Singapore:

17. Turner TR, James EK, Poole PS. The plant microbiome. Genome Biol. 2013;14:1-10.

18. Vandenkoornhuyse P, Quaiser A, Duhamel M, Le Van A, Dufresne A. The importance of the microbiome of the plant holobiont. New Phytol. 2015;206:1196-1206.

19. Qiu Z, Egidi E, Liu H, Kaur S, Singh BK. New frontiers in agriculture productivity: Optimised microbial inoculants and in situ microbiome engineering. Biotechnol Adv. 2019;37:107371.

20. Peyraud R, Dubiella U, Barbacci A, Genin S, Raffaele S, Roby D. Advances on plant-pathogen interactions from molecular toward systems biology perspectives. The Plant J. 2017;90:720-737.

21. Pascale A, Proietti S, Pantelides IS, Stringlis IA. Modulation of the root microbiome by plant molecules: the basis for targeted disease suppression and plant growth promotion. Front Plant Sci. 2020;10:1741.

22. Canarini A, Kaiser C, Merchant A, Richter A, Wanek W. Root exudation of primary metabolites: mechanisms and their roles in plant responses to environmental stimuli. Front Plan Sci. 2019;10:157. 
23. Tkacz A, Pini F, Turner TR, Bestion E, Simmonds J, Howell P, Greenland A, Cheema J, Emms DM, Uauy C. Agricultural selection of wheat has been shaped by plant-microbe interactions. Front Microbiol. 2020;11:132.

24. Wassermann B, Cernava T, Müller H, Berg C, Berg G. Seeds of native alpine plants host unique microbial communities embedded in cross-kingdom networks. 2019;7:108.

25. Oyserman BO, Medema MH, Raaijmakers JM. Road MAPs to engineer host microbiomes. Curr Opin Microbiol. 2018;43:46-54.

26. Velmourougane K, Saxena G, Prasanna R. Plant-microbe interactions in the rhizosphere: mechanisms and their ecological benefits. Springer, Singapore, 2017. p. 193-219.

27. Ke J, Wang B, Yoshikuni Y. Microbiome Engineering: synthetic biology of plant-associated microbiomes in sustainable agriculture. Trends Biotechnol. 2020. https://doi.org/10.1016/j.tibtech.2020.07.008

28. Bouhnik Y, Attar A, Joly F, Riottot M, Dyard F, Flourie B. Lactulose ingestion increases faecal bifidobacterial counts: a randomised double-blind study in healthy humans. Eur J Clin Nutr. 2004;58:462-466.

29. Flint HJ, Scott KP, Louis P, Duncan SH. The role of the gut microbiota in nutrition and health. Nat Rev Gastroenterology Hepatol. 2012;9:577.

30. Sanders ME, Merenstein DJ, Reid G, Gibson GR, Rastall RA. Probiotics and prebiotics in intestinal health and disease: from biology to the clinic. Nat Rev Gastroenterology Hepatol. 2019;16:605-616.

31. Davani-Davari D, Negahdaripour M, Karimzadeh I, Seifan M, Mohkam M, Masoumi SJ, Berenjian A, Ghasemi Y. Prebiotics: definition, types, sources, mechanisms, and clinical applications. 2019;8:92.

32. Carlson JL, Erickson JM, Lloyd BB, Slavin JL. Health effects and sources of prebiotic dietary fiber. CDN. 2018;2:nzy005.

33. den Besten G, van Eunen K, Groen AK, Venema K, Reijngoud DJ, Bakker BM. The role of short-chain fatty acids in the interplay between diet, gut microbiota, and host energy metabolism. J Lipid Res. 2013;54:2325-2340..

34. Du Jardin P.. Plant biostimulants: definition, concept, main categories and regulation. Sci Hortic. 2015;196:3-14.

35. Van Oosten MJ, Silletti S, Guida G, Cirillo V, Di Stasio E, Carillo P, Woodrow P, Maggio A, Raimondi G. A benzimidazole proton pump inhibitor increases growth and tolerance to salt stress in tomato. Front Plant Sci. 2017;8:1220.

36. Halpern M, Bar-Tal A, Ofek M, Minz D, Muller T, Yermiyahu U. The use of biostimulants for enhancing nutrient uptake. In Advances in agronomy.Academic press, p. 141-174.

37. Mukherjee A, Patel J. Seaweed extract: biostimulator of plant defense and plant productivity. Int J Environ Sci Te. 2020;17:553-558.

38. Calvo P, Nelson L, Kloepper JW. Agricultural uses of plant biostimulants. Plant Soil. 2014; 383:3-41. 
39. Kim D, Jeon C, Shin J, Weller DM, Thomashow L, Kwak Y. Function and distribution of a lantipeptide in strawberry Fusarium wilt disease-suppressive soils. Mol Plant Microbe In. 2019;32:306-312.

40. Hartmann A, Rothballer M, Schmid M. Lorenz Hiltner, A pioneer in rhizosphere microbial ecology and soil bacteriology research. Plant Soil. 2008;312:7-14.

41. Zilber-Rosenberg I, Rosenberg E. Role of microorganisms in the evolution of animals and plants: the hologenome theory of evolution. FEMS Microbiol Rev. 2008;32:723-735.

42. Rosenberg E, Zilber-Rosenberg I. Microbes drive evolution of animals and plants: the hologenome concept. 2016;7:e01395-15.

43. Gibson GR, Hutkins R, Sanders ME, Prescott SL, Reimer RA, Salminen SJ, et al. Expert consensus document: The International Scientific Association for Probiotics and Prebiotics (ISAPP) consensus statement on the definition and scope of prebiotics. Nat Rev Gastroenterol. 2017;14:491.

44. Wang S, Xiao Y, Tian F, Zhao J, Zhang H, Zhai Q, Chen W. Rational use of prebiotics for gut microbiota alterations: Specific bacterial phylotypes and related mechanisms. J Funct Foods. 2020;66:103838.

45. Bindels LB, Delzenne NM, Cani PD, Walter J. Towards a more comprehensive concept for prebiotics. Nat Rev Gastroenterology Hepatol. 2015;12:303.

46. Gurry T, Gibbons SM, Kearney SM, Ananthakrishnan A, Jiang X, Duvallet C, et al. Predictability and persistence of prebiotic dietary supplementation in a healthy human cohort. Sci Rep. 2018;8:1-13.

47. Babbar N, Dejonghe W, Gatti M, Sforza S, Elst K. Pectic oligosaccharides from agricultural byproducts: production, characterization and health benefits. Crit Rev Biotechnol. 2016;36:594-606.

48. Stringlis IA, De Jonge R, Pieterse CM. The age of coumarins in plant-microbe interactions. Plant Cell Physiol. 2019;60:1405-1419.

49. Voges MJEEE, Bai Y, Schulze-Lefert P, Sattely ES. Plant-derived coumarins shape the composition of an Arabidopsis synthetic root microbiome. PNAS. 2019;116:12558-12565.

50. Legay N, Baxendale C, Grigulis K, Krainer U, Kastl E, Schloter M, Bardgett RD, Arnoldi C, Bahn M, Dumont M. Contribution of above-and below-ground plant traits to the structure and function of grassland soil microbial communities. Ann Bot. 2014;114:1011-1021.

51. Rodríguez Amor D, Dal Bello M. Bottom-up approaches to synthetic cooperation in microbial communities. 2019;9:22.

52. Zhao C, Wu Y, Liu X, Liu B, Cao H, Yu H, Sarker SD, Nahar L, Xiao J. Functional properties, structural studies and chemo-enzymatic synthesis of oligosaccharides. Food Sci Technol. 2017;66:135-145.

53. Jin HE, Choi JC, Lim YT, Sung MH. Prebiotic effects of poly-gamma-glutamate on bacterial flora in murine gut. J Microbiol Biotechnol. 2017;27:412-415

54. Romano AH, Nickerson WJ. Utilization of amino acids as carbon sources by Streptomyces fradiae. J Bacteriol .1958;75:161-166.

55. Trivedi P, Leach JE, Tringe SG, Sa T, Singh BK: Plant-microbiome interactions: from community assembly to plant health. Nat Rev Microbiol. 2020:1-15. https://doi.org/10.1038/s41579-020-0412-1 
56. Garrido-Oter R, Nakano RT, Dombrowski N, Ma K, Team TA, McHardy AC, Schulze-Lefert P. Modular traits of the Rhizobiales root microbiota and their evolutionary relationship with symbiotic rhizobia. Cell Host Microbe. 2018;24:155-167. e5.

57. Paik M, Lee J, Kim K. N-Ethoxycarbonylation combined with (S)-1-phenylethylamidation for enantioseparation of amino acids by achiral gas chromatography and gas chromatography-mass spectrometry. J Chromatogr A. 2008;1214:151-156.

58. Paik M, Cho I, Mook-Jung I, Lee G, Kim. Altered free amino acid levels in brain cortex tissues of mice with Alzheimer's disease as their $\mathrm{N}(\mathrm{O}, \mathrm{S})$-ethoxycarbonyl/tert-butyldimethylsilyl derivatives. BMB Rep. 2008;41:23-28.

59. Yoon Y, Kuppusamy S, Cho KM, Kim PJ, Kwack Y, Lee YB. Influence of cold stress on contents of soluble sugars, vitamin $\mathrm{C}$ and free amino acids including gamma-aminobutyric acid (GABA) in spinach (Spinacia oleracea). Food Chem. 2017; 215:185-192.

60. Hobbie EA, Watrud LS, Maggard S, Shiroyama T, Rygiewicz PT. Carbohydrate use and assimilation by litter and soil fungi assessed by carbon isotopes and BIOLOG® assays. Soil Biol Biochem. 2003;35:303-311.

61. Petrasch S, Knapp SJ, Van Kan JA, Blanco-Ulate B. Grey mold of strawberry, a devastating disease caused by the ubiquitous necrotrophic fungal pathogen Botrytis cinerea. Mol Plant Pathol. 2019;20:877-892

62. Nam MH, Park MS, Kim HS, Kim TI, Kim HG. Cladosporium cladosporioides and tenuissimum cause blossom blight in strawberry in Korea. Mycobiology 2015;43:354-359.

63. Coats $\mathrm{JH}$, Argoudelis AD. Microbial transformation of antibiotics: phosphorylation of clindamycin by Streptomyces coelicolorJ Bacteriol. 1971;108:459-464.

64. Hamid ME. Variable antibiotic susceptibility patterns among Streptomyces species causing actinomycetoma in man and animals. Ann Clin Microb Anti. 2011;10:24.

65. Williams S. Sensitivity of Streptomycetes to antibiotics as a taxonomic character. Microbiology 1967;46:151-160.

66. Schlatter DC, Kinkel LL. Global biogeography of Streptomyces antibiotic inhibition, resistance, and resource use. FEMS Microbiol Ecol. 2014;88:386-397.

67. Asif $\mathrm{MH}$, Dhawan P, Nath P. A simple procedure for the isolation of high quality RNA from ripening banana fruit. Plant Mol Biol Rep. 2000;18:109-115.

68. Breitler J, Campa C, Georget F, Bertrand B, Etienne H. A single-step method for RNA isolation from tropical crops in the field. Sci Rep. 2016;6:1-6.

69. Zhang Y, Peng X, Liu Y, Li Y, Luo Y, Wang X, et al. Evaluation of suitable reference genes for qRT-PCR normalization in strawberry (Fragariax ananassa) under different experimental conditions. BMC Mol Biol. 2018;19:8.

70. Amil-Ruiz F, Garrido-Gala J, Gadea J, Blanco-Portales R, Muñoz-Mérida A, Trelles O, et al. Partial activation of SA-and JA-defensive pathways in strawberry upon Colletotrichum acutatumFront Plant Sci. 2016;7:1036. 
71. Besbes F, Habegger R, Schwab W. Induction of PR-10 genes and metabolites in strawberry plants in response to Verticillium dahliaeBMC plant biol. 2019;19:128.

72. Løvdal T, Lillo C. Reference gene selection for quantitative real-time PCR normalization in tomato subjected to nitrogen, cold, and light stress. Anal Biochem. 2009;387:238-242.

73. Harel YM, Mehari ZH, Rav-David D, Elad Y. Systemic resistance to gray mold induced in tomato by benzothiadiazole and Trichoderma harzianumPhytopathology 2014;104:150-157.

74. Tucci M, Ruocco M, De Masi L, De Palma M, Lorito M. The beneficial effect of Trichoderma on tomato is modulated by the plant genotype. Mol Plant Pathol. 2011;12:341-354.

\section{Additional Information}

\section{Additional file 1:}

Supplementary Figure 1. Chemical constituents of strawberry flower exudate,

Supplementary Figure 2. Biolog phenotype array for nitrogen utilization and bacterial growth.

Supplementary Figure 3. Experimental design in the strawberry greenhouse.

Supplementary Figure 4. Gray mold and blossom blight disease incidence.

Supplementary Figure 5. Dynamics of strawberry flower microbial communities as influenced by amino acids.

Supplementary Figure 6. Metacoder analysis of the microbial composition of strawberry flowers among treatments (untreated, $2 \%$ L-glutamic acid, $2 \%$ L-asparagine).

Supplementary Figure 7. Functional gene orthology profiles among untreated (green bar), L-asparagine (green bar), and L-glutamic acid (blue bar) treated strawberry flowers.

Supplementary Figure 8. Suppression of Fusarium wilt disease of tomato by strain SP6C4 with or without L-glutamic acid.

Supplementary Figure 9. Comparison of the tomato rhizosphere microbiome at the family level.

Supplementary Figure 10. Co-occurrence networks among the top 10 OTUs in the tomato rhizosphere based on lanM gene copy number.

Supplementary Figure 11. Microbial engineering with $L$-glutamic acid for control of Fusarium wilt disease of tomato.

Supplementary Figure 12. Microbial engineering with $L$-glutamic acid $(5 \mu \mathrm{g} / \mathrm{mL})$ for control of strawberry gray mold disease, 
Supplementary Figure 13. Relative expression of ISR-related and PAMP marker genes in the strawberry flower and tomato rhizosphere as determined by qRT-PCR.

\section{Additional file 2:}

Supplementary Table 1 Optical density of PM1 plate for carbon sources (96-well format)

Supplementary Table 2 Optical density of PM3B plate for nitrogen sources (96-well format)

Supplementary Table 3 Number of sequencing read counts of strawberry flower samples

Supplementary Table 5 Number of sequencing read counts of tomato rhizosphere samples

Supplementary Table 7 GenBank accession numbers for strawberry flower sample pyrosequencing

Supplementary Table 8 qRT-PCR primers of ISR related genes

\section{Additional file 3:}

Supplementary Table 4 Strawberry anthosphere metagenome OTU data

\section{Additional file 4:}

Supplementary Table 6 Tomato rhizosphere metagenome OTU data

\section{Figures}


a

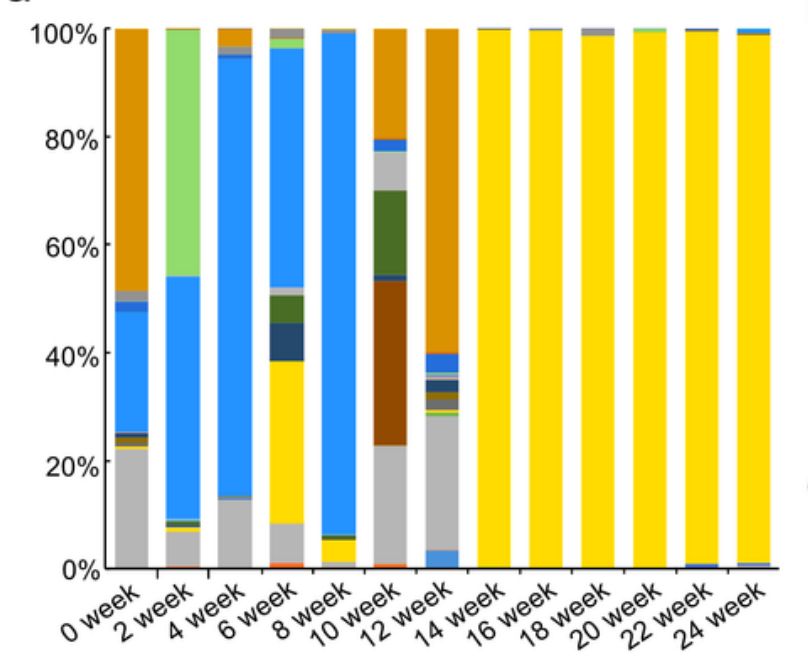

\section{Top 10 OTUs}

Proteobacteria

Pseudomonadaceae Enterobacteriaceae

Sphingomonadaceae Burkholderiaceae

Alcaligenaceae

d

Xanthomonadaceae Rhizobiaceae

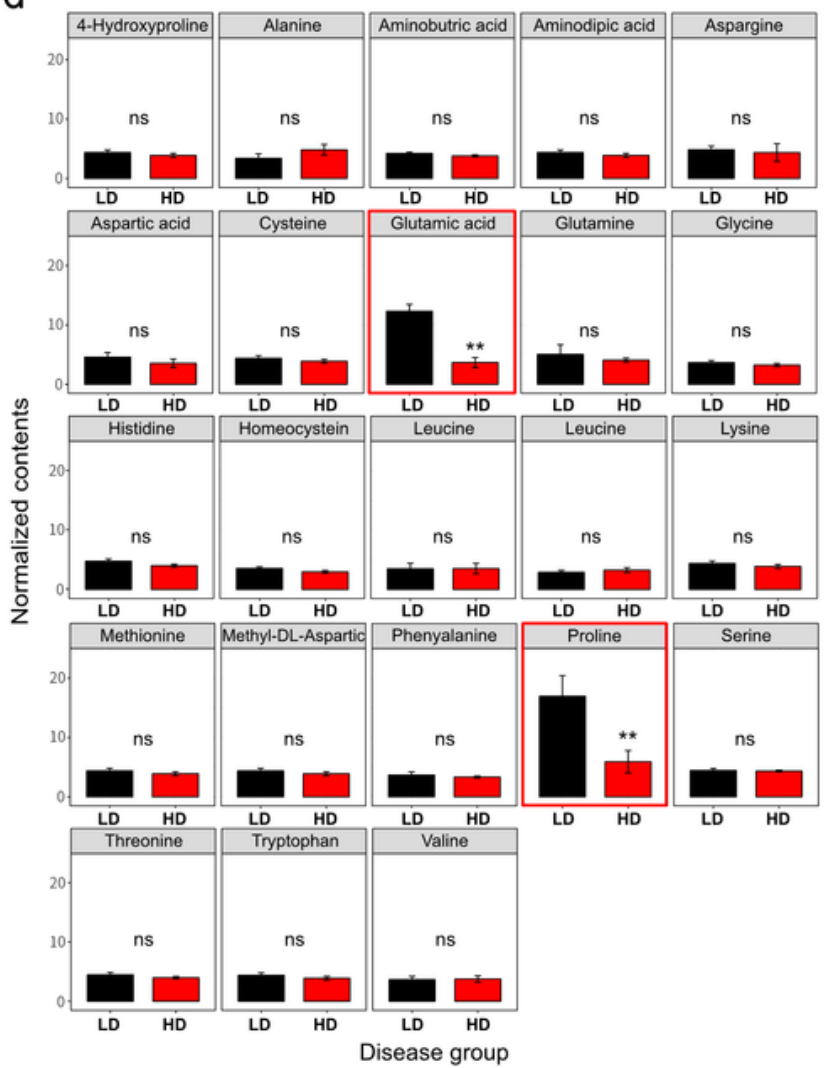

b
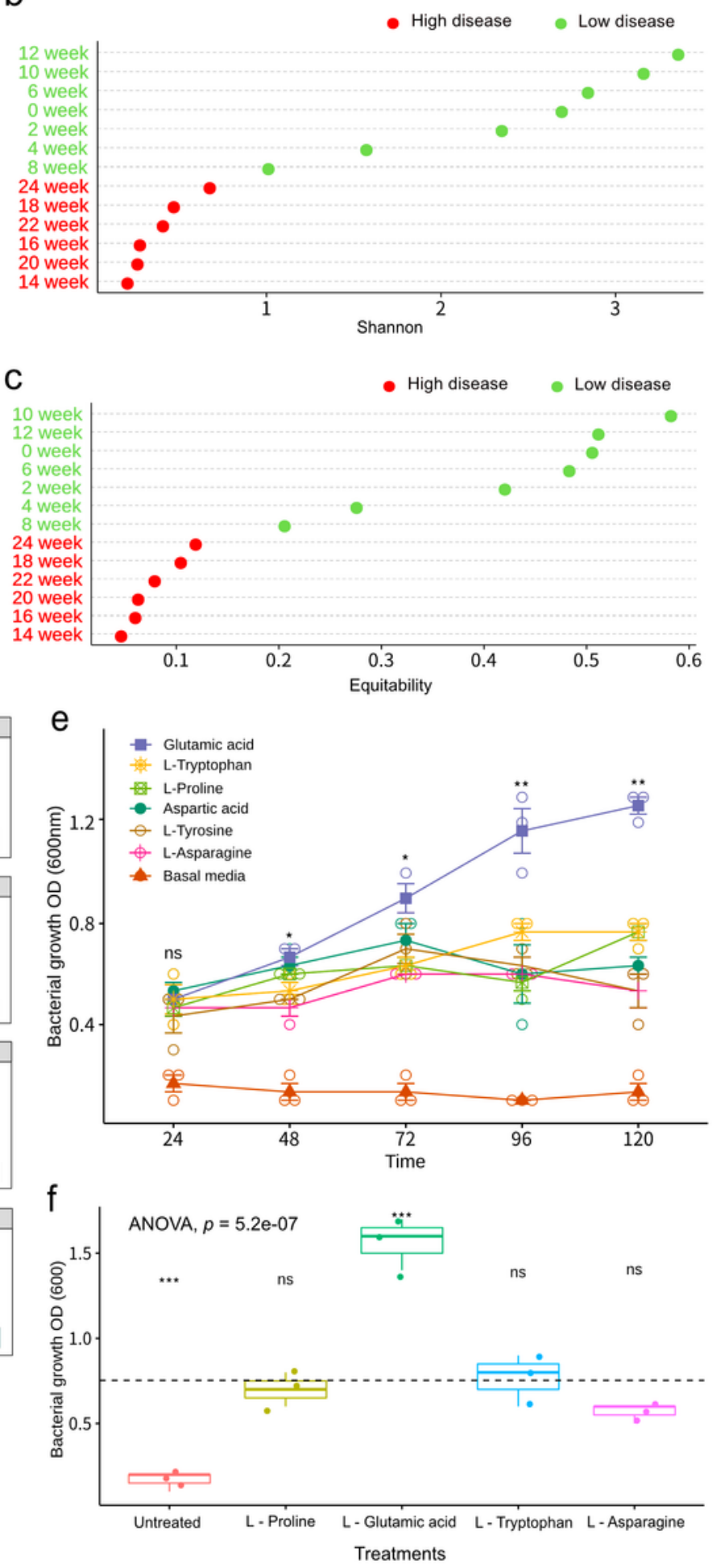

\section{Figure 1}

Amino acid content of strawberry flower petal tissues. Microbial community collapse in the strawberry anthosphere (Kim et al. 2019). a Microbiome diversity of strawberry flowers ( $n=9,13$ independent experiments). Strawberry (cv. Maehyang) flowers were collected from week 0 (Nov. 2013) to week 24 (Apr. 2014). Top 10 OTUs at the family level based on the Silva database (http://www.arb-silva.de/) and a cutoff of $97 \%$ similarity. b, c OTU alpha diversity over time according to Shannon's diversity and 
equitability indices relative to gray mold disease incidence. $d$ Content of 23 amino acids in strawberry flower petals ( $n=3,8$ independent experiments). Normalized concentrations of amino acids were compared by independent t-test $(P$ value $<0.05)$. Black and red bars indicate periods of low and high disease incidence, respectively. e Growth of S. globisporus SP6C4 in basal medium supplemented with amino acids. A bacterial suspension ( $100 \mu \mathrm{L}, 0 D 600 \mathrm{~nm} 0.02)$ was inoculated into basal medium supplemented with amino acids in a 96-well plate and incubated on an orbital shaker at $150 \mathrm{rpm}$ and $28^{\circ} \mathrm{C}$ for 5 days $(n=3,3$ independent experiments). $f$ Bacterial growth with $2 \%$ amino acid amendments. Bars represent the standard error and stars indicate Tukey's HSD test, statistically significant differences among treatments $\left({ }^{*} P<0.05,{ }^{\star} \mathrm{P}<0.01,{ }^{\star * \star} \mathrm{P}<0.001\right)$. 
a

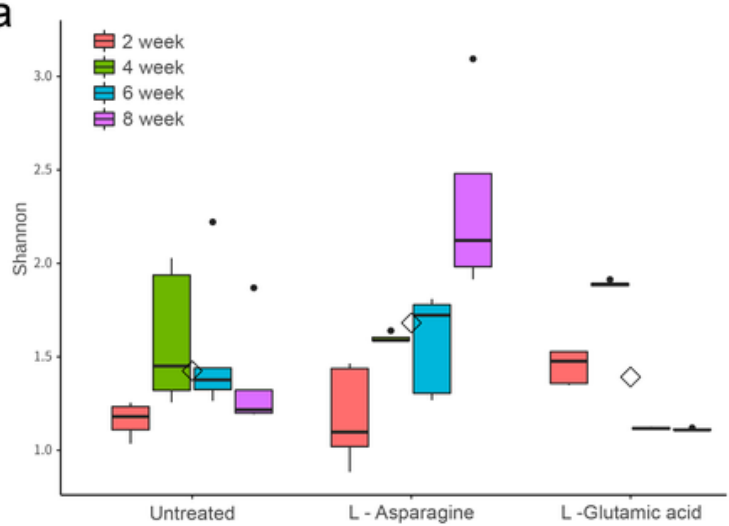

b

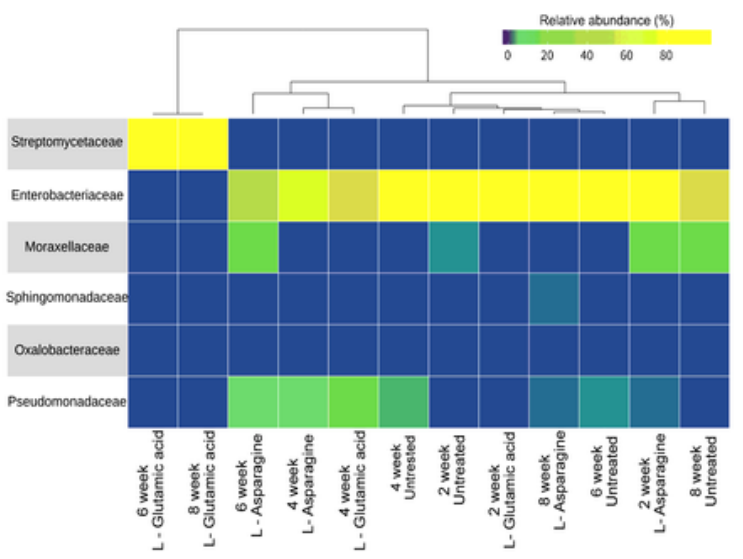

C

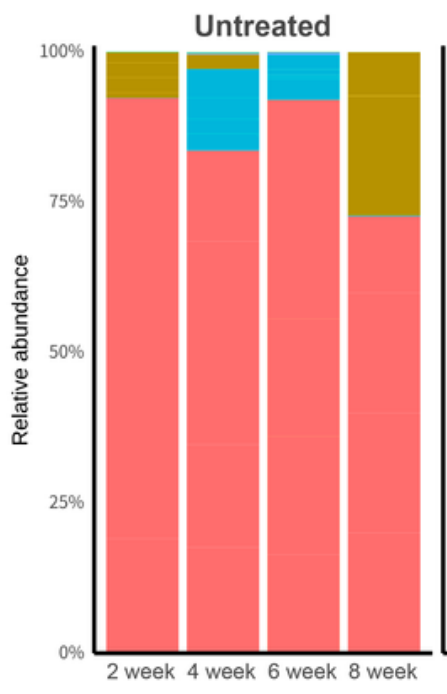

L - Asparagine

L - Glutamic acid
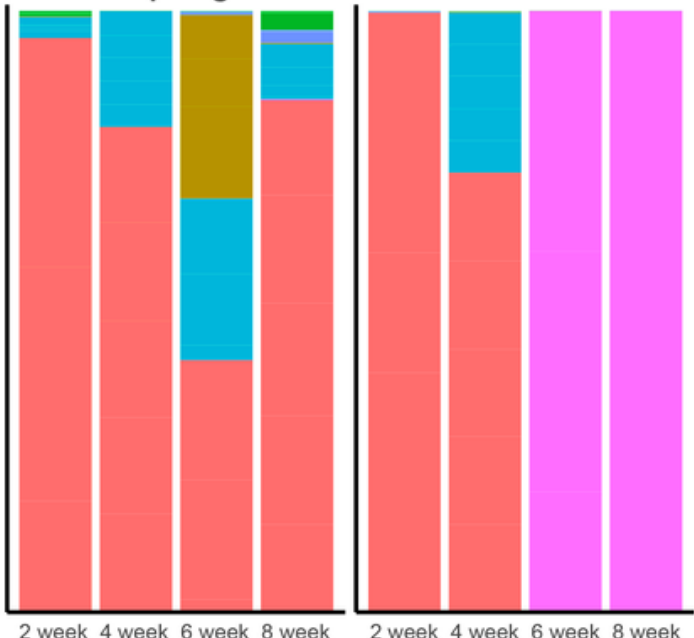

Family

Enterobacteriaceae

Moraxellaceae

Others

Pseudomonadaceae

Sphingomonadaceae

Streptomycetaceae

d

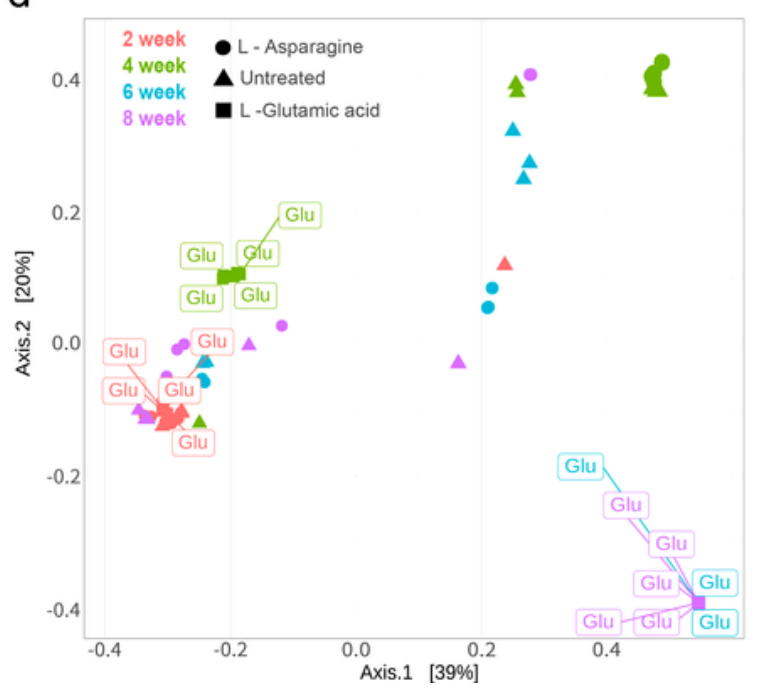

e

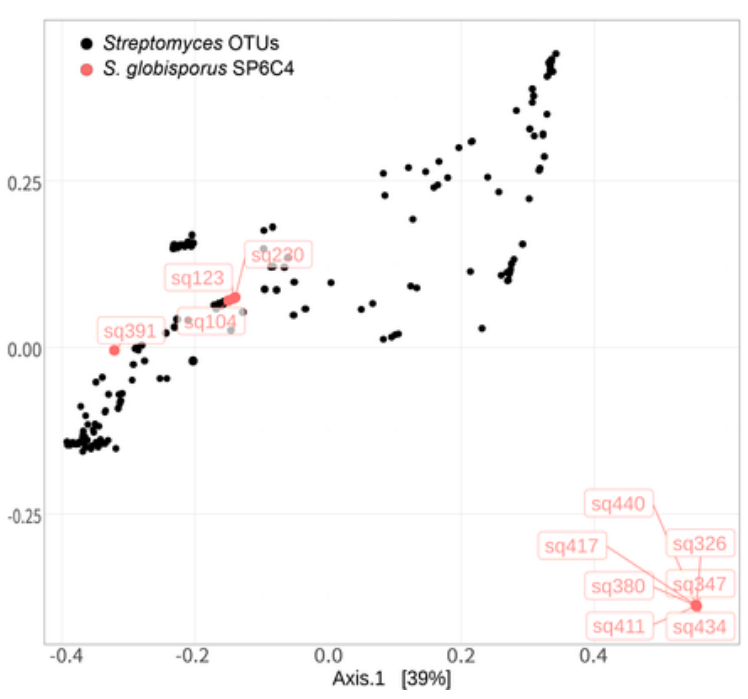

Figure 2

Microbial diversity in the strawberry flower is shifted by different amino acid treatments. a Box plot of alpha diversity. Samples were collected from December, 2017 to February, 2018 and amino acids were sprayed from Jan, 2018 to Feb, 2018 weeks 4, 6 and 8). Each treatment included five plots of 100 plants ( $n=5,12$ independent experiments). $b$ Similarity of microbial abundance by hierarchical clustering of the variable region of $16 \mathrm{~S}$ rRNA with a beta diversity tree (Minkowski distance method). Heatmap color 
(purple to yellow) displays low to high abundance of each OTU. c Sequencing of the microbes associated with strawberry flowers ( $n=5,12$ independent experiments). Taxonomic assignment was conducted at the family level in Silva database (http://www.arb-silva.de/) with a similarity cutoff of $97 \%$ confidence. d, e PCoA plots of beta diversity (Bray-Curtis distance); each sample was vectorized to spatial position and dark circles in e covered OTUs overlapping those of Streptomyces globisporus SP6C4 (identities $>98 \%$ ). Bars represent the standard error.
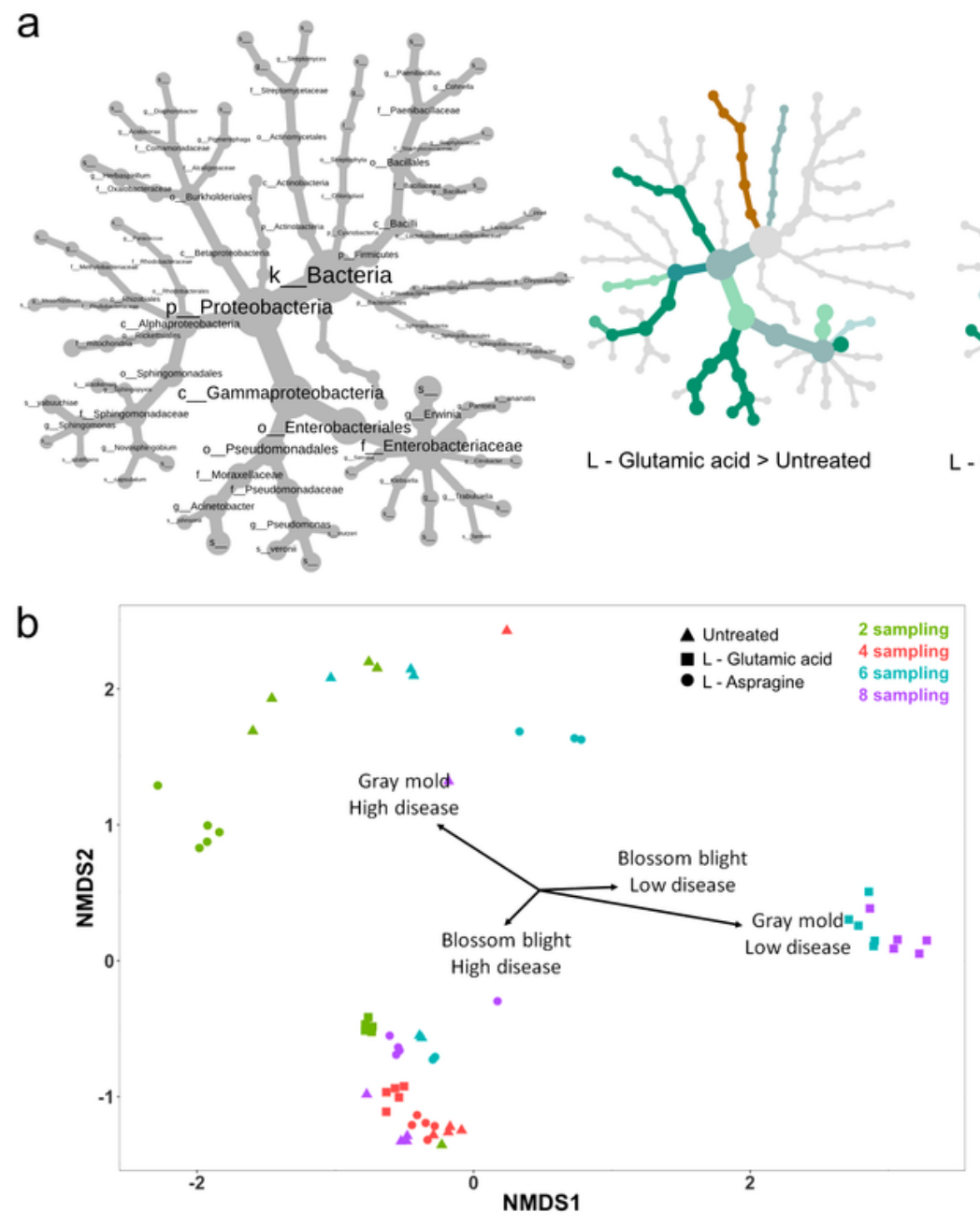

C
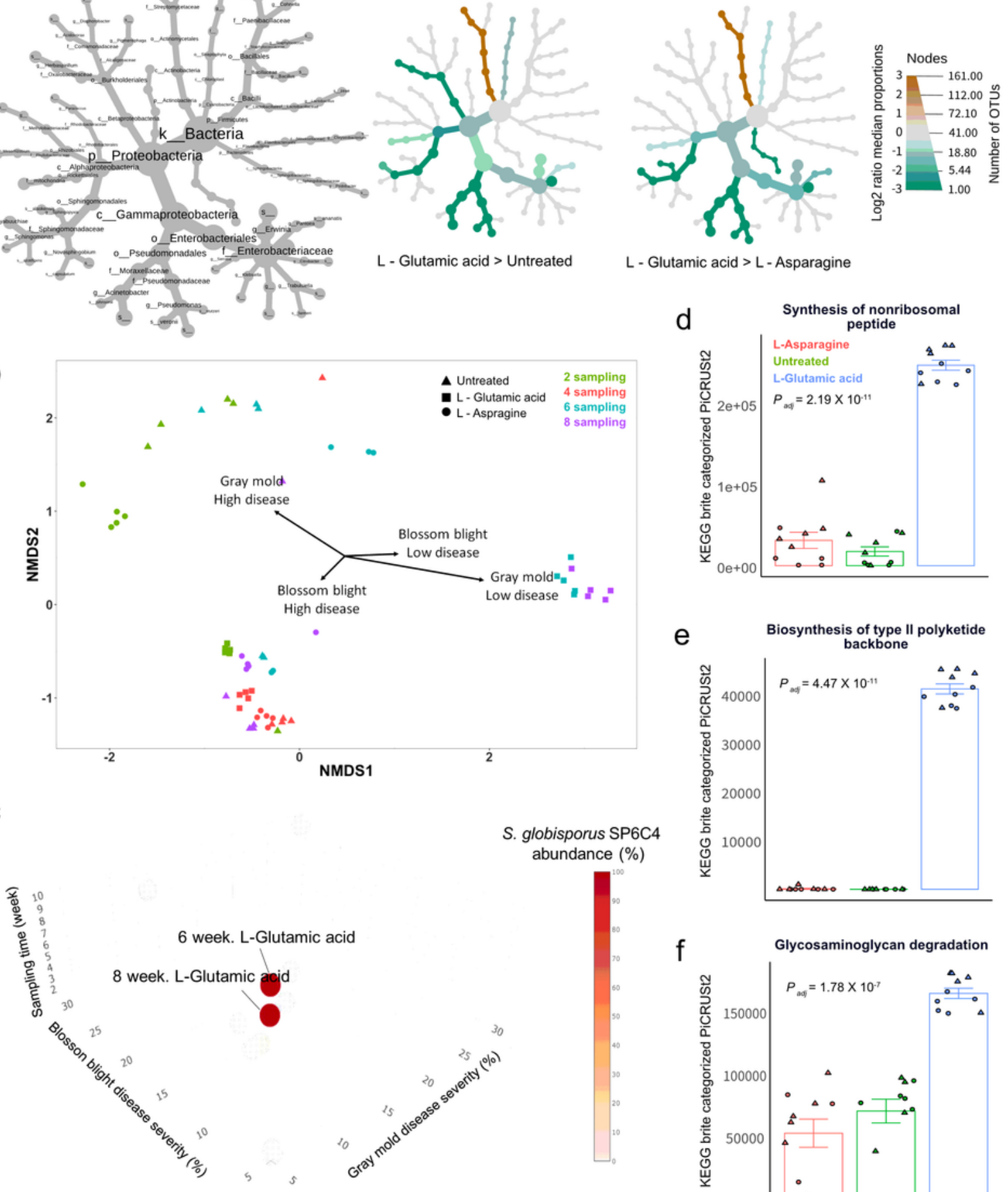

L - Glutamic acid > L - Asparagine
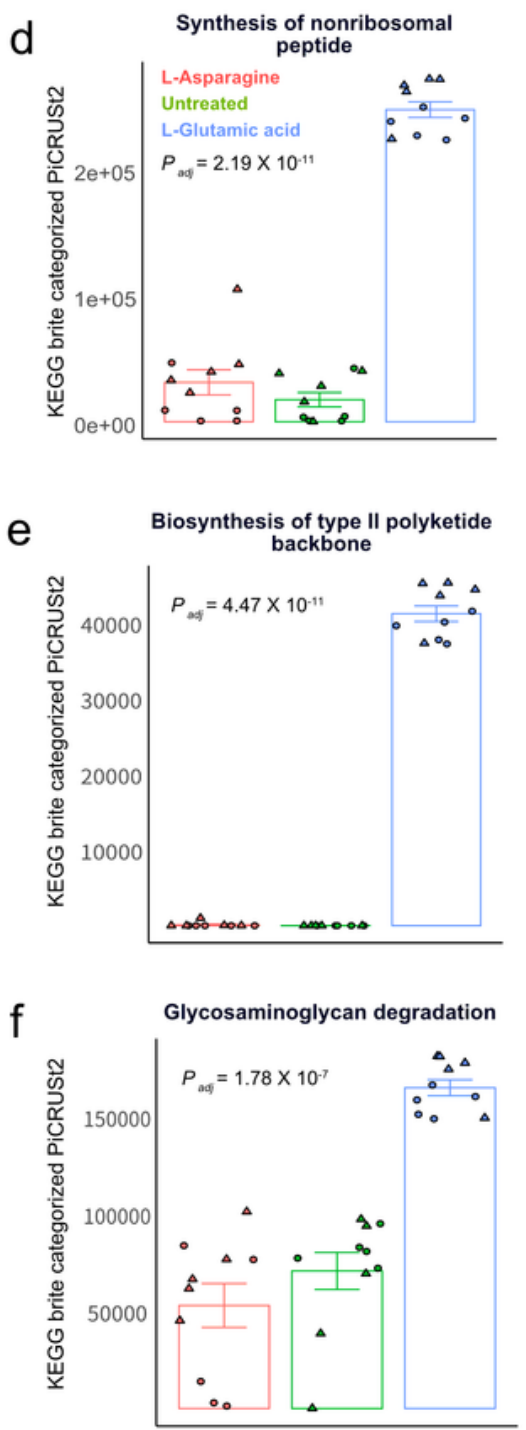

Figure 3 
Changes in microbial community structure coincident with amino acid treatment and correlation with disease occurrence. a Phylotrees showing diversity of microbial OTUs in L-glutamic acid-treated flowers contrasted with diversity in untreated flowers or flowers sprayed with L- asparagine (Metacoder v 0.3.0.1). Size of the nodes refers of the relative abundance and color represents a significant change in relative abundance. b Ordination plot of NMDS analysis based on microbial diversity and relative abundance of OTUs ( $n=5,12$ independent experiments). Four vectors correspond to disease incidence variables (for each block, $n=100$ plants, 5 blocks represent independent experiments). For gray mold, low disease was $<15 \%$ and high disease incidence was $16 \%$ to $30 \%$. Low incidence of blossom blight was $<20 \%$ and high incidence was $21 \%$ to $30 \%$. c 3D models; $x$ vector represents blossom blight disease incidence; $y$ vector represents gray mold disease incidence and $z$ vector represents Streptomyces OTUs. The majority of Streptomyces 16 S rRNA sequences had $98 \%$ identity in each of 12 samples compared with the incidence of each of the two different diseases. $d$-f Alteration to functional profiles derived from sequencing of microbial communities from strawberry flowers. Functional pathways were inferred from OTUs by using PICRUSt (v. 3. 6. 6) and annotated with the KEGG database. Differences by PICRUSt analysis between the L-glutamic acid treatment and the untreated control were compared by the Likelihood Ratio method (A more than B) with log2-fold change (cutoff with $p$ adj value $>0.001$ in LRT model). 


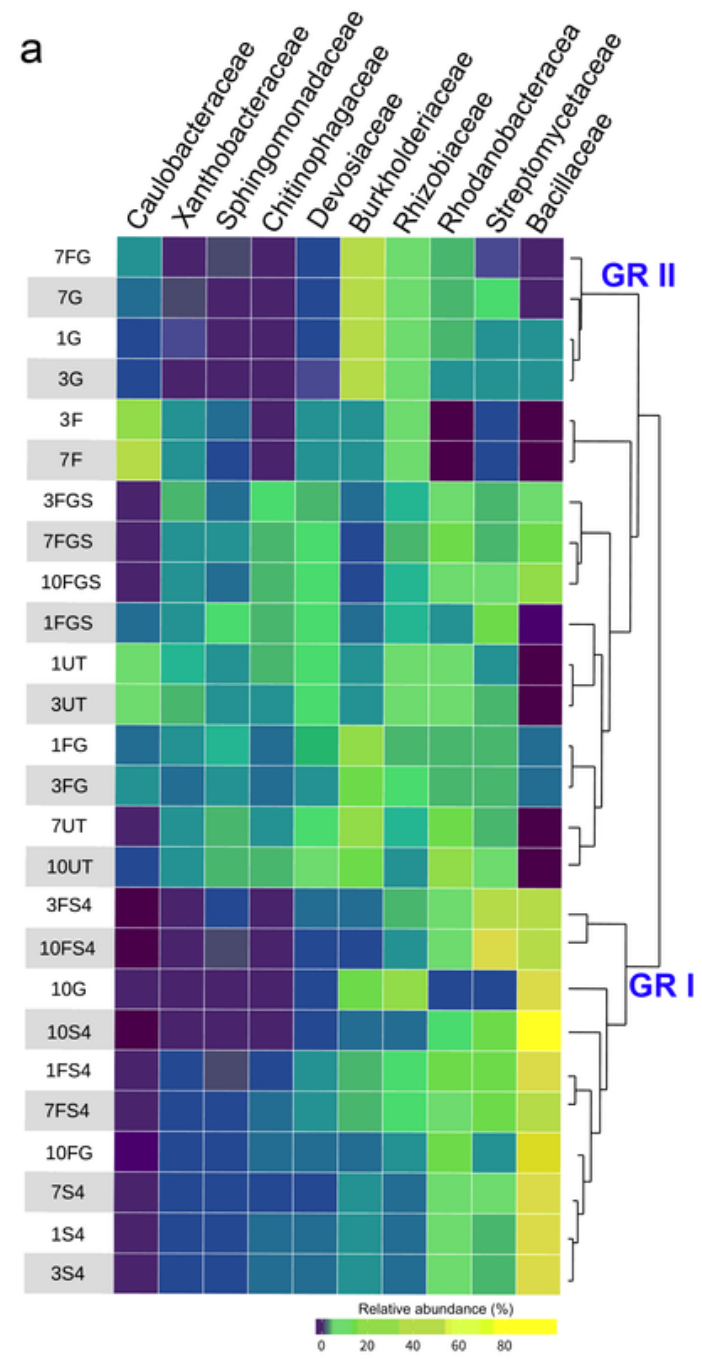

b
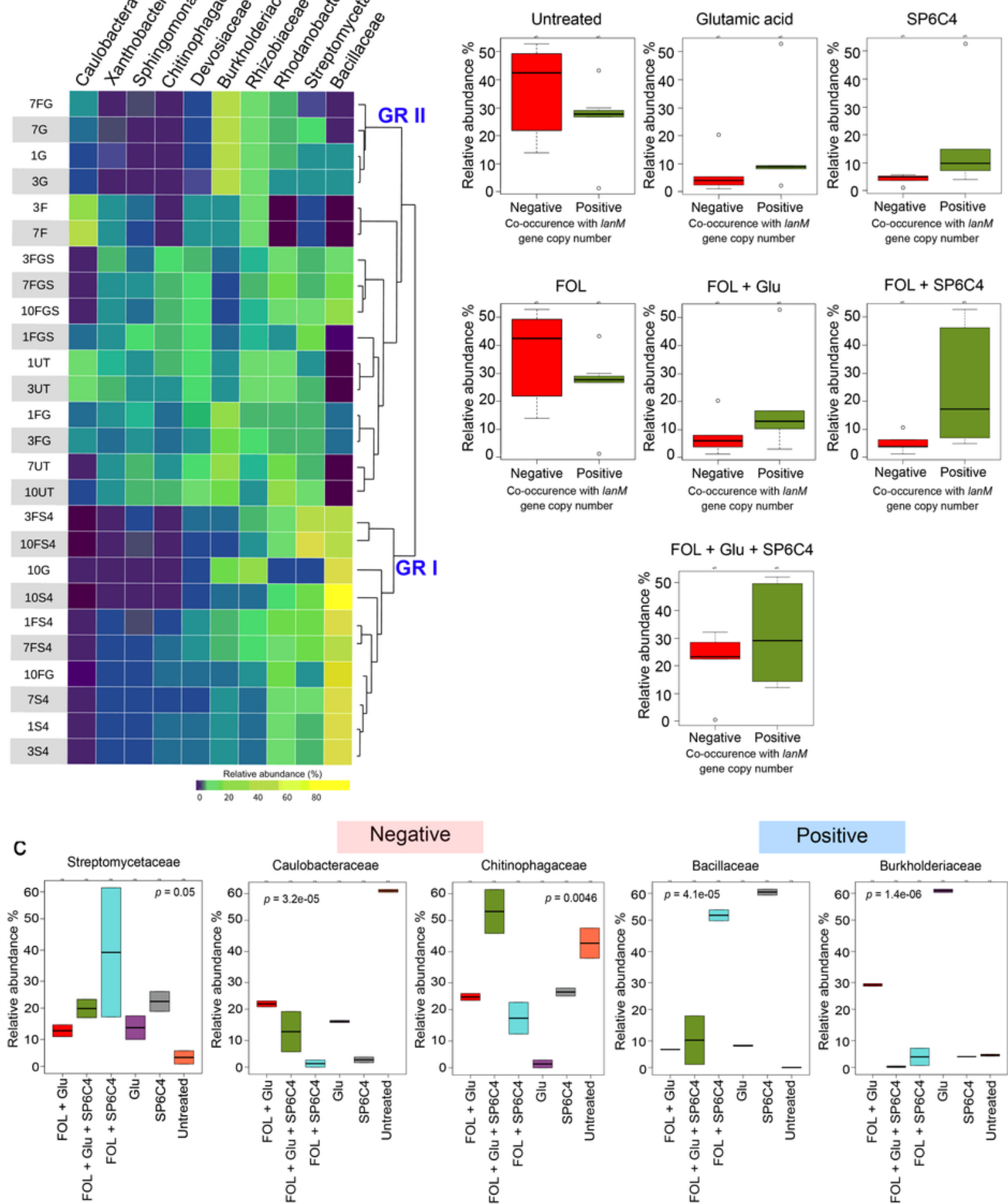

Negative
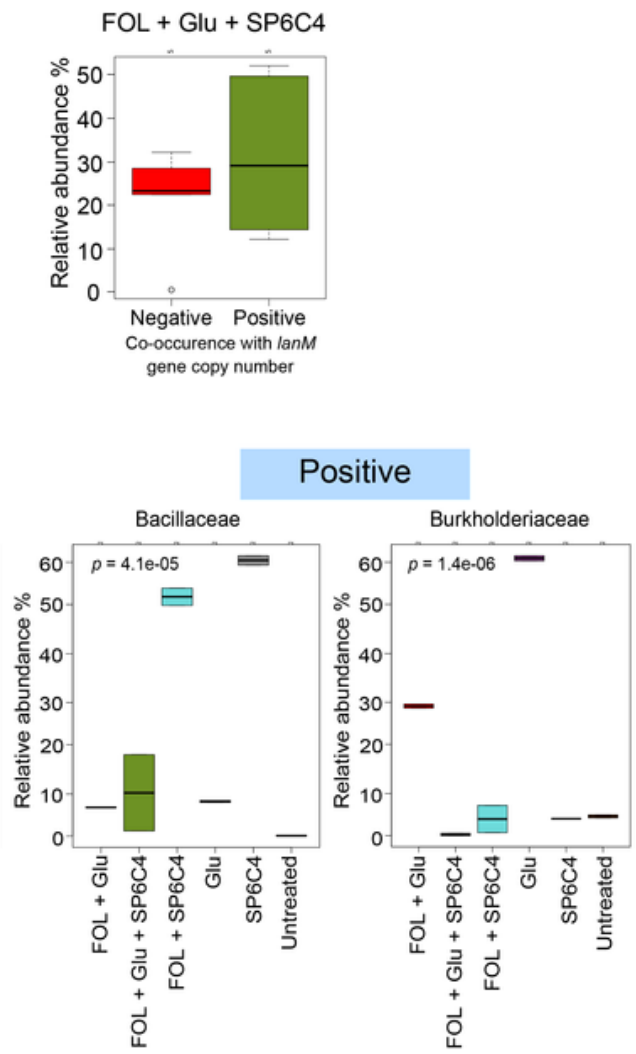

\section{Figure 4}

OTU abundance at the family level of two different co-occurrence groups relative to the lanM copy number. Tomato plants were cultured in a plant growth chamber for 10 weeks $\left(16 \mathrm{~h}\right.$ : Light, $25^{\circ} \mathrm{C}, 8 \mathrm{~h}$ : Dark, $\left.22^{\circ} \mathrm{C}\right)$. L-Glutamic acid $50 \mathrm{~mL}(5 \mu \mathrm{g} / \mathrm{mL})$ was drenched at 1 and 2 weeks and $30 \mathrm{~mL}$ of S. globisporus SP6C4 $(107 \mathrm{cfu} / \mathrm{mL})$ in $0.1 \%$ methylcellulose was added at the base of the plant at 4 weeks. At 5 weeks, conidia of F. oxyporum f. sp. lycopersici (FOL, $105 \mathrm{cfu} / \mathrm{mL}$ ) were inoculated. Rhizosphere samples were 
collected at 1, 3, 7 and 10 weeks and each treatment had 5 plants $(n=5,26$ independent experiments). a Distribution heatmap of microbial abundance ordered by hierarchical clustering with 16S rRNA. Heatmap color (purple to yellow) corresponds to OTU abundance from low to high. The tree on the right was created by the Minkowski distance method. b Negative group: Caulobacteraceae, Chitinophagaceae, Positive group: Bacillaceae, Burkholderiaceae, Streptomycetaceae, a Boxes present average relative abundance with standard error of OTUs in each of six treatments at 3 week $(n=5$, Independent sample ttest: Untreated, $\mathrm{P}=0.16$; Glutamic acid, $\mathrm{P}=0.38 ; \mathrm{SP} 6 \mathrm{C} 4, \mathrm{P}=0.14 ; \mathrm{FOL}, \mathrm{P}=0.17, \mathrm{FOL}+\mathrm{Glu}, \mathrm{P}=0.29 ; \mathrm{FOL}$ $+\mathrm{SP} 6 \mathrm{C} 4, \mathrm{P}=0.12 ; \mathrm{FOL}+\mathrm{Glu}+\mathrm{SP} 6 \mathrm{C} 4, \mathrm{P}=0.35) . c$ Variation in abundance of the major OTUs relative to the core microbe and wilt disease sensitivity after treatment with $\mathrm{L}$-glutamic acid $(5 \mu \mathrm{g} / \mathrm{mL})$. Mean relative abundance at 1 and 3 weeks before disease inoculation $(n=2,6$ independent replications) and numeric values are results of ANOVA with Tukey's HSD analysis and error bars represent \pm SE. 

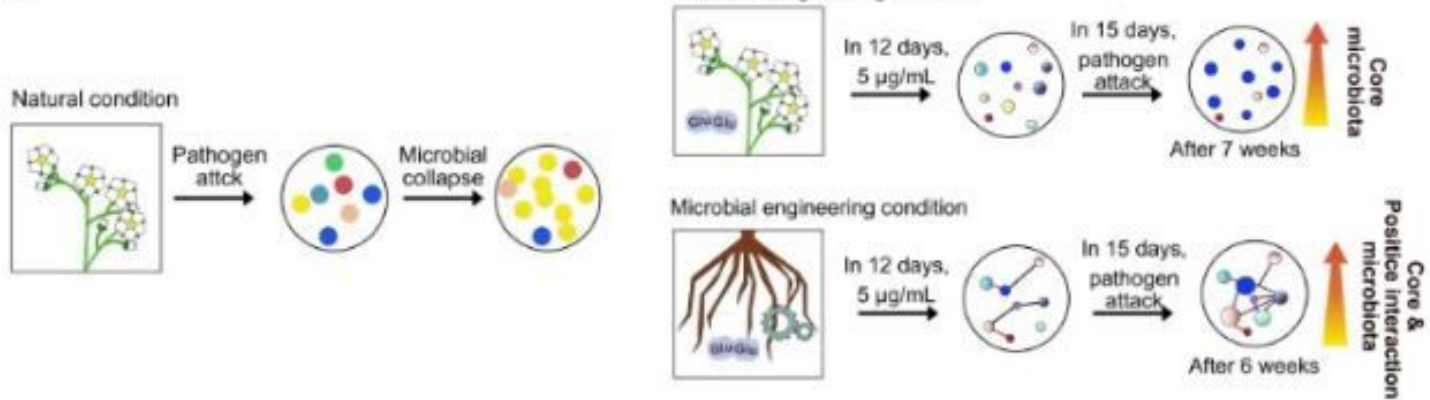

b

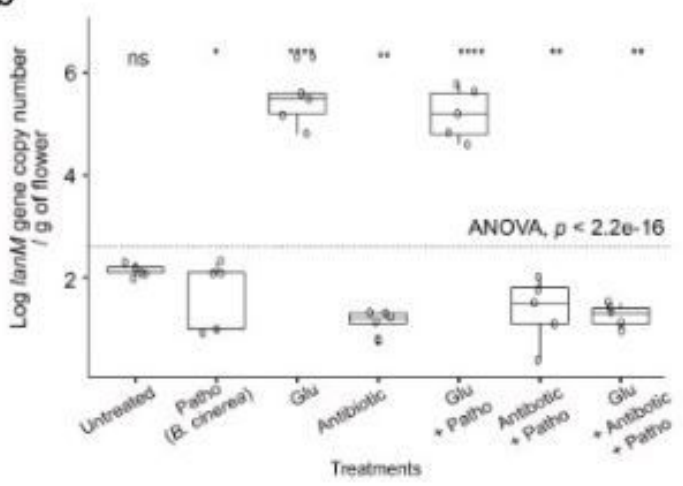

d

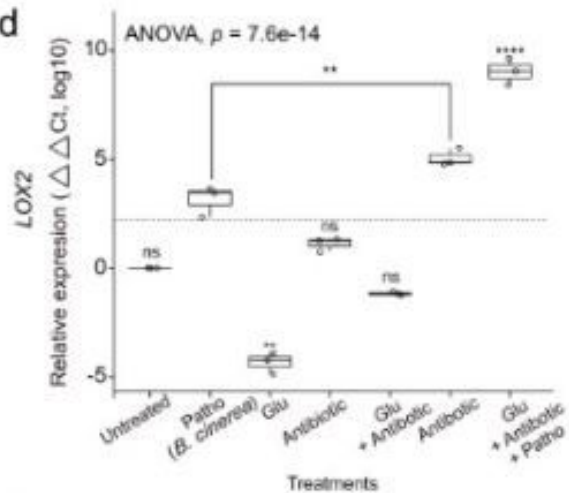

f

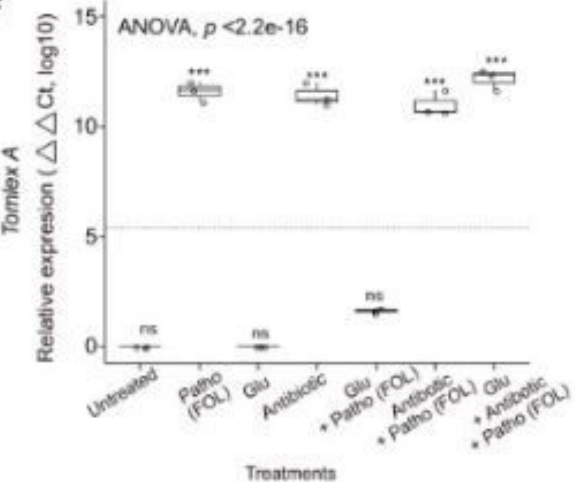

C

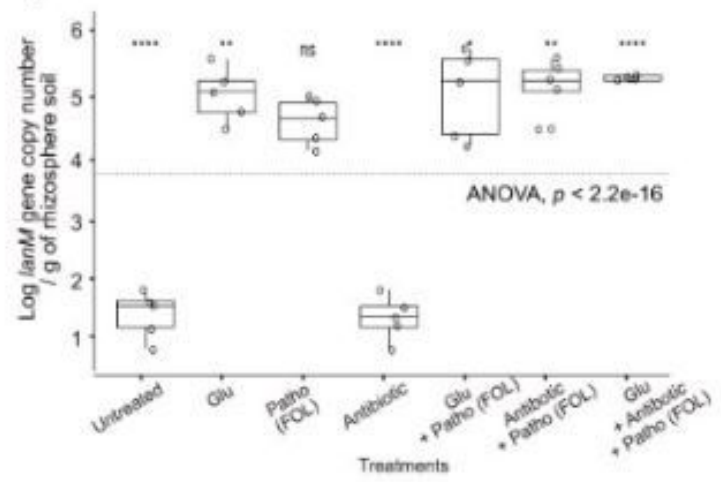

e
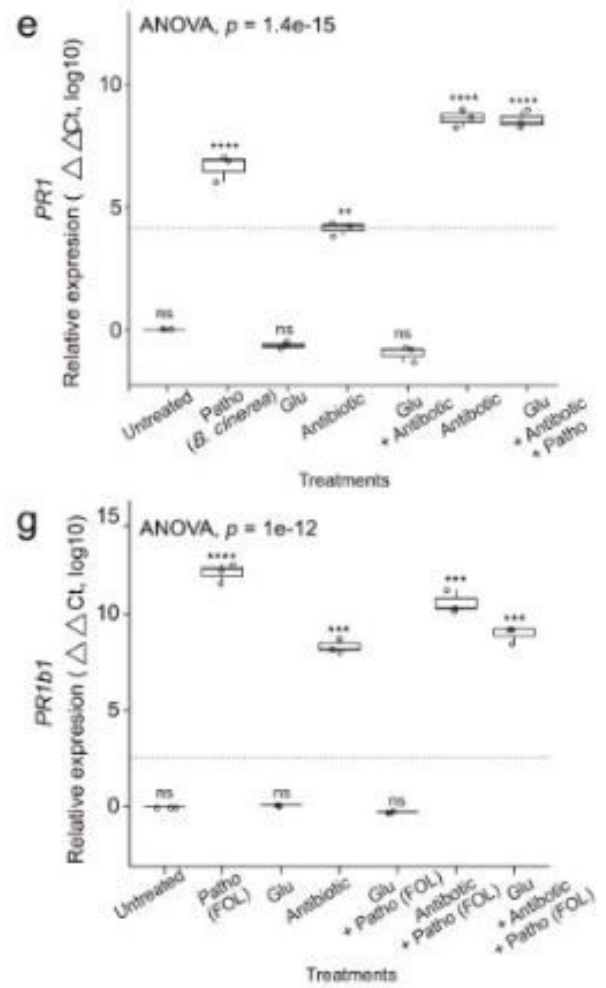

\section{Figure 5}

Microbial engineering with L-glutamic acid $(5 \mu \mathrm{g} / \mathrm{mL})$ for both of strawberry anthosphere and tomato rhizosphere without ISR related functions. a microbial engineering experiment design in the strawberry anthosphere and tomato rhizosphere. b Copy number of the SP6C4-specific lanM gene on strawberry flowers was determined by qRT-PCR ( $n=5$, technical replication). c lanM gene specific copy number on tomato rhizosphere by qRT-PCR ( $n=5$, technical replication). Relative expression level of $d$ JA- and e SA- 
responsive genes in strawberry. Untreated control received $50 \mathrm{~mL}$ of $0.1 \%$ Hoagland's solution treated flowers (Sprayed) with L-glutamic acid $(5 \mu \mathrm{g} / \mathrm{mL}$ ) and antibiotics (erythromycin and clindamycin: each at $10 \mu \mathrm{g} / \mathrm{mL})$. After 3 days, a stock of B. cinerea conidia ( $105 \mathrm{cfu} / \mathrm{mL})$ was sprayed on the flower surface. Flower samples were collected into 2-mL bead tubes 7 weeks later and RNA was extracted by a one-step extraction method $(n=5)$. Expression levels of the $f J A$ reporter genes and levels of the $g$ SA reporter genes in tomato. After 3 days, a stock of FOL conidia $(105 \mathrm{cfu} / \mathrm{mL})$ was drenched on the soil.

Rhizosphere samples were collected into 2-mL bead tubes 6 weeks later and RNA was extracted $(n=5)$. qPCR was performed with cDNA in a SYBR green Mastermix and included three technical replications. Gene expression was calculated by the $\triangle \triangle \mathrm{ct}$ method using relative to GAPDH in strawberry and tubulin as a housekeeping gene in tomato. Data represent means $\pm S E(n=5)$ and stars indicate statistically significant differences by ANOVA with Tukey's HSD test.

\section{Supplementary Files}

This is a list of supplementary files associated with this preprint. Click to download.

- Additionalfile1.docx

- Additionalfile2.docx

- Additionalfile3.docx.xlsx

- Additionalfile4.docx.xIsx 